SAND81-8259

Unlimited Release

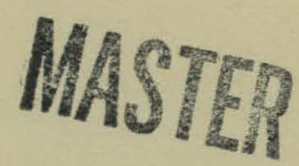

\title{
An Evaluation of the Current Status of Hydrogen Embrittlement and Stress- Corrosion Cracking in Steels
}

N. R. Moody

Prepared by Sandia National Laboratories, Albuquerque, New Mexico 87185 and Livermore, California 94550 for the United States Department of Energy under Contract DE-AC04-76DP00789.

Printed December 1981

\section{Sandia National Laboratories}




\section{DISCLAIMER}

This report was prepared as an account of work sponsored by an agency of the United States Government. Neither the United States Government nor any agency Thereof, nor any of their employees, makes any warranty, express or implied, or assumes any legal liability or responsibility for the accuracy, completeness, or usefulness of any information, apparatus, product, or process disclosed, or represents that its use would not infringe privately owned rights. Reference herein to any specific commercial product, process, or service by trade name, trademark, manufacturer, or otherwise does not necessarily constitute or imply its endorsement, recommendation, or favoring by the United States Government or any agency thereof. The views and opinions of authors expressed herein do not necessarily state or reflect those of the United States Government or any agency thereof. 


\section{DISCLAIMER}

Portions of this document may be illegible in electronic image products. Images are produced from the best available original document. 
Issued by Sandia Laboratories, operated for the United States Department of Energy by Sandia Corporation.

\section{NOTICE}

This report was prepared as an account of work sponsored by the United States Government. Neither the United States nor the United States Department of Energy, nor any of their employees, nor any of their contractors, subcontractors, or their employees, makes any warranty, express or implied, or assumes any legal liability or responsibility for the accuracy, completeness or usefulness of any information, apparatus, product or process disclosed, or represents that its use would not infringe privately owned rights. 


\section{PAGES 1 to 2 WERE INTENTIONALLY LEFT BLANK}




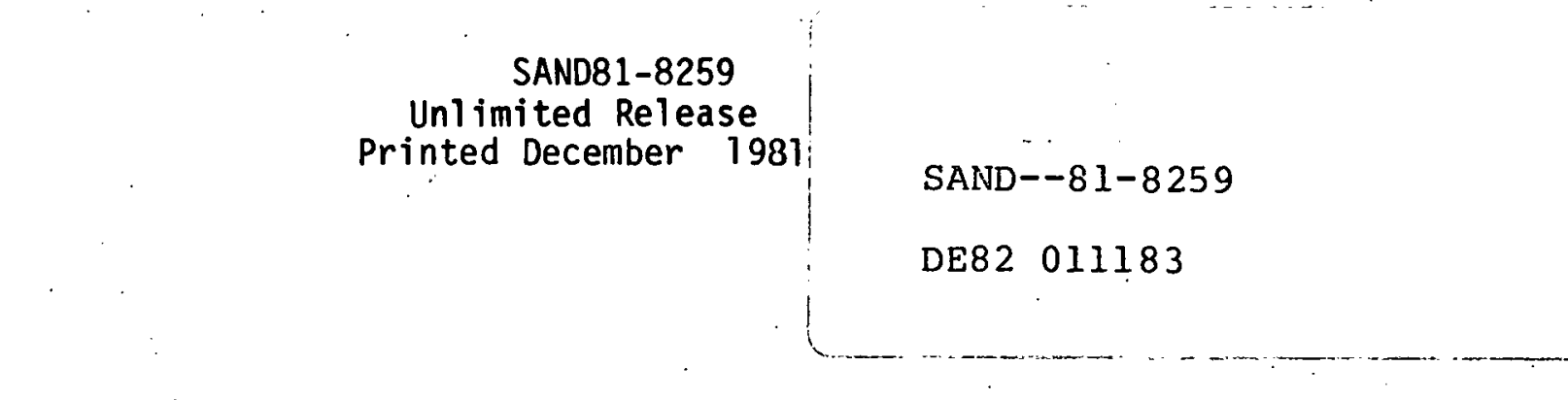

AN EVALUATION OF THE CURRENT STATUS OF HYDROGEN EMBRITTLEMENT AND STRESS-CORROSION CRACKING IN STEELS

Neville R. Moody

Materials Development Division II

Sandia National Laboratories, Livermore

\begin{abstract}
A review of recent studies on hydrogen embrittlement and stress corrosion cracking in steels shows there are several critical areas where data is either ambiguous, contradictory, or non-existent. A relationship exists between impurity segregation and hydrogen embrittlement effects but it is not known if the impurities sensitize a preferred crack path for hydrogeninduced failure or if impurity and hydrogen effects are additive. Furthermore, grain boundary impurities may enhance susceptibility through interactions with some environments. Some studies show that an increase in grain size increases susceptibility; at least one study shows an opposite effect. Recent work also shows that fracture initiates at different locations for external and internal hydrogen environments. How this influences susceptibility is unknown. The difficulty in identifying the rate-controlling mechanism for fracture is demonstrated by the change in threshold behavior with high pressures in a hydrogen gas environment. This change may be due to a trapping effect. . The effect of hydrogen trapping on crack initiation and growth needs further study to define its influence on susceptibility. Fundamental research is required to fully understand these aspects to improve alloy design and use.
\end{abstract}

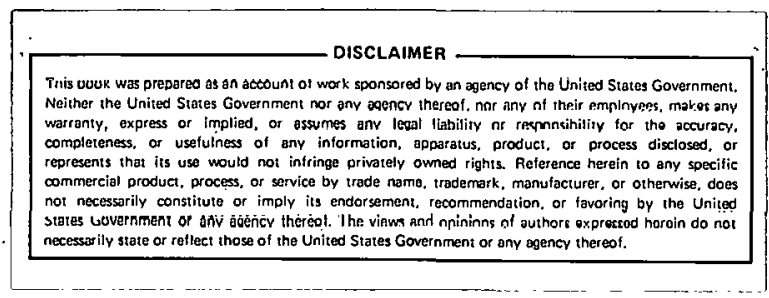

CotRIBUtIOH OF THIS DOCUMENT IS UMLHATE

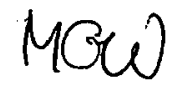




\section{CONTENTS}

Page

Introduction $\quad \cdots 7$

Composition 8

$\begin{array}{ll}\text { Microstructure } & 13\end{array}$

Grain Size $\quad 14$

Environmental Effects 21

Hydrogen Gas $\quad 21$

Internal Hydrogen 26

$\begin{array}{ll}\text { Stress Corrosion Cracking - Aqueous Environments } & 27\end{array}$

Hydrogen Transport 28

Dislocation Transport 28

Stress-Assisted Diffusion $\quad 28$

Experimental Observations $\quad 29$

Hydrogen Diffusivity, Solubility and Partial Molar Volune 29

$\begin{array}{ll}\text { Trapping } & 30\end{array}$

Summary and Recommendations 32

Acknowledgements $\quad 34$

References : $\quad 35$ 


\section{List of Figures}

1 The effect of bulk impurity concentration on hydrogen-induced thresholds for commercial 4340 .

2. The relationship of grain size to fracture toughness for commercial 4340 .

3. The relationship of 4340 Charpy V-notch (CVN) energy to grain size.

4. The effect of grain size on hydrogen-induced thresholds in various hydrogen environments for commercial 4340 .

5. The effect of grain boundary impurity concentration on hydrogen-induced thresholds in commercial 4340.

6. As grain boundary impurity concentration increases, CVN energy decreases. At a low grain boundary concentration; fracture changes from microvoid coalescence to intergranular failure.

7. The influence of hydrogen pressure on threshold behavior for commercial 4340 with yield strengths ranging from 1070 to $1720 \mathrm{MPa}$.

8. Thresholds for high yield strength materials normalized on yield s.trength.

9. Austenitic stainless steel and superalloy thresholds follow a common plot with yield stress. The data was obtained in hydrogen gas at pressures of 100 and $200 \mathrm{MPa}$.

10. The temperature behavior of hydrogen diffusivity for a number of iron and steel alloys. The solid lines represent the boundary curves for the data of Volki and Alefeld ${ }^{81}$. 
AN EVALUATION OF THE CURRENT STATUS OF HYDROGEN EMBRITTLEMENT AND STRESS CORROSION CRACKING IN STEELS

\section{Introduction}

Previous work ${ }^{1-3}$ shows that hydrogen embrittlement (HE) and stress corrosion cracking $(S C C)$ depend on geometrical, stress intensity, environmental and material variables. In simple systems the effects of individual variables can be isolated. However, in complex systems individual effects may be altered by other variables or even masked. ${ }^{4}, 5$ For example, temper and hydrogen embrittlement exhibit similar behavior. ${ }^{4}$ Does grain boundary searegation sensitize a preferred path for hydrogen-induced cracking or are impurity and hydrogen effects additive? ${ }^{6-8}$ Do grain boundary impurities, which act as catalysts for anodic dissolution and hydrogen generation in some aqueous environments, ${ }^{9}, 10$ change $H E / S C C$ susceptibility of an alloy from one environment to another? Some studies $11-13$ show that an increase in grain size enhances HE/SCC susceptibility while at least one study finds an opposite effect. ${ }^{5}$ Is this effect an impurity, environmental or mechanical effect? How do hydrogen transport and trapping affect susceptibility and failure? Answers to these questions will permit improved alloy design and use.

HE/SCC susceptibility is usually characterized by the degradation of a material's mechanical properties through tensile, slow strain-rate and impact tests. For susceptible materials such as bcc irons and steels, these t.ests provide a comparison of relative susceptibility. When materials are subjected to long term use in aggressive environments, the relative susceptibilities from short term tests do not provide a reliable indication of a material's behavior. For these applications, tests to determine slow. crack growth behavior are required. Most slow crack growth tests have been done on susceptible bcc alloys. However, bcc steel results exhibit crack growth behavior that can occur in austenitic stainless steels and superalloys under severe environmental conditions. From this point of view, the following review will discuss grain boundary segregation, grain size, hydrogen transport and hydrogen trapping effects. 
Alloy composition has a strong effect on a material's susceptibility to hydrogen embrittlement and stress corrosion cracking. The determination of. an alloying element's influence on HE/SCC is difficult in a complex alloy system because an element's behavior often differs from that observed in a simple system. ${ }^{3}$ Table I summarizes the effects of the major alloying elements on environmental susceptibility for iron and steel alloys. The data is drawn from and presented in the style of the reviews by Gerberichl and Bernstein and Thompson ${ }^{3}, 4$ along with the results of recent

studies. 14-29 The reader is referred to these reviews for a more thorough discussion of alloying effects.

Carbon and manganese generally increase the susceptibility of iron and steel alloys to environmental cracking whereas silicon, molybdenum and titanium either decrease or have little effect on susceptibility. However, titanium can increase the environmental susceptibility of maraging steels through $\gamma^{\prime}$ precipitation. ${ }^{3}, 4$ The influence of nickel varies with concentration. At low concentrations, nickel enhances susceptibility while at large concentrations the tendency for environmental cracking is reduced.22-24 The type, size and distribution of carbides can also enhance or inhibit $\mathrm{HE} / \mathrm{SCC}$ susceptibility. ${ }^{4}, 23$

The effect of impurity elements is also very important in establishing an alloy's susceptibility to both environmental cracking and temper embrittlement. Impurities are generally detrimental but the severity of their effect depends on thermal treatment, 11 microstructure, $3,4,30$ impurity and alloy concentrations ${ }^{1}, 31$ and yield strength. ${ }^{32}$ There appears to be an interrelationship between hydrogen and temper embrittlement ${ }^{4}$ which is currently receiving a considerable amount of attention. ${ }^{8}, 11,33$ The major question emerges: Does grain boundary segregation of impurity elements sensitize a preferential path for hydrogen-induced cracking or are hydrogen effects additive to impurity effects?

The impurity elements of phosphorus and sulfur degrade both the temper and environmental performance of steels. Banerji et al. ll find a five-fold increase in hydrogen-induced thresholds when the phosphorus concentration is substantially reduced. Even in a relatively pure steel with $0.004 \% \mathrm{~S}$ and $0.004 \% \mathrm{P}$, embrittlement is significant 27 as shown in Figure 1 for $4340.5,11-13,34$ For impurity concentrations above $0.01 \mathrm{wt} . \%$, increasing sulfur and phosphorus concentrations have no effect on HE susceptibility. Below 0.01 wt.\% thresholds increase significantly as impurity concentration decreases. A recent study 35 indicates that a phosphorus concentration less than $100 \mathrm{ppm} w \mathrm{t}$. is needed to avoid temper embrittlement and therefore reduce environmental susceptibility. Furthermore, dissociated sulfur acts as a cathodic poison which enhances HE/SCC. This is observed in Ni (200) where sulfur on the grain boundaries catalyzes anodic dissolution in a sulfuric acid solution enhancing hydrogen generation and absorption.9 Arsenic, ${ }^{4}$ antimony ${ }^{36},{ }^{37}$ and $\operatorname{tin}^{38}$ also cause temper embrittlement. As with sulfur and phosphorus, these impurities enhance susceptibility and the severity of hydrogen embrittlement in steel. 
TABLE I.

THE EFFECT OF COMPOSITION ON HE/SCC SUSCEPTIBILITY

\begin{tabular}{|c|c|c|c|c|c|c|}
\hline Element & Alloy & Environment & $\begin{array}{l}\text { General } \\
\text { Susceptibility }\end{array}$ & Threshold & $\begin{array}{l}\text { Crack } \\
\text { Growth }\end{array}$ & Comments \\
\hline \multirow[t]{2}{*}{ C } & $\begin{array}{l}\mathrm{Fe} \\
\mathrm{Fe}-\mathrm{Ni}\end{array}$ & $\begin{array}{l}\text { cathodically charged } \\
\text { nitrate sol'ns }\end{array}$ & increases & - & - & $\begin{array}{l}\text { severity and extent } \\
\text { of cracking increases } \\
\text { while failure time } \\
\text { decreases }(14-16)\end{array}$ \\
\hline & $\begin{array}{l}4340 \\
\gamma-S S\end{array}$ & $\begin{array}{l}\text { cathodically charaed } \\
\mathrm{H}_{2} \text { gas, } 3.5 \% \mathrm{NaCl} \\
\mathrm{Cl} \text { sol'ns }\end{array}$ & $\begin{array}{l}\text { increases } \\
\text { decreases }\end{array}$ & decreases & - & $\begin{array}{l}\text { minimum in threshold } \\
\text { at } 0.4 \% \mathrm{C}(3,17,18) \\
\text { above } 0.1-0.2 \% \\
\text { increases time to } \\
\text { failure }(19)\end{array}$ \\
\hline \multirow[t]{2}{*}{ Carbides } & $\begin{array}{l}4340,4130 \\
\text { martens } i- \\
\text { tic and } \\
\gamma-S S\end{array}$ & $\begin{array}{l}\text { cathodically charged } \\
\mathrm{H}_{2} \text { gas }\end{array}$ & $\begin{array}{l}\text { increases } \\
\text { (grain bound- } \\
\text { ary carbides) }\end{array}$ & $\begin{array}{l}\text { decreases } \\
\text { (grain boun- } \\
\text { ary carbides) }\end{array}$ & - & $\begin{array}{l}\text { very susceptible when } \\
\text { carbides are along } \\
\text { prior } \gamma \text { boundaries }\end{array}$ \\
\hline & $\mathrm{Fe}-\mathrm{C}-\mathrm{Ti}$ & & $\begin{array}{l}\text { decreases } \\
\text { (homogeneous } \\
\text { distribution) }\end{array}$ & - & $\begin{array}{l}\text { may } \\
\text { decrease }\end{array}$ & $\begin{array}{l}\text { reduces susceptibility } \\
\text { if carbides homogen- } \\
\text { eously distributed } \\
(23)\end{array}$ \\
\hline $\mathrm{Ti}$ & $\begin{array}{l}\text { Fe-C } \\
\text { maraging } \\
\text { steel }\end{array}$ & $\begin{array}{c}\text { cathodically charged } \\
\text {. }\end{array}$ & $\begin{array}{l}\text { decreases } \\
\text { increases }\end{array}$ & $\begin{array}{l}- \\
-\end{array}$ & $\begin{array}{l}\text { may } \\
\text { decrease } \\
-\end{array}$ & $\begin{array}{l}\text { reduces extent and } \\
\text { severity of cracking } \\
\text { (14) promotes } \gamma^{\prime} \text { pre- } \\
\text { cipitation which pro- } \\
\text { motes susceptibility } \\
\text { (4) }\end{array}$ \\
\hline $\mathrm{Ni}$ & $\begin{array}{l}\mathrm{Fe} \\
<2 \% \mathrm{Ni} \\
<4 \% \mathrm{Ni} \\
\mathrm{Fe}-18 \mathrm{Cr} \\
10-25 \% \mathrm{Ni} \\
<8 \% \mathrm{Ni}\end{array}$ & $\begin{array}{l}\text { nitrate sol'ns. } \\
\mathrm{NaCl} \text { sol'n. } \\
22 \% \mathrm{NaCl}^{\prime} \\
42 \% \mathrm{MgCl}_{2}\end{array}$ & $\begin{array}{l}\text { increases } \\
\text { little effect } \\
\text { increases } \\
\text { increases }\end{array}$ & $\begin{array}{l}\text { little effect } \\
\text { decreases } \\
-\end{array}$ & $\begin{array}{l}- \\
- \\
-\end{array}$ & $\begin{array}{l}(16) \\
(17) \\
\text { susceptibility } \\
\text { decreases above } 25 \% \mathrm{Ni} \\
(22) \\
\text { susceptibility de- } \\
(24)^{2} \text { ses above } 8 \% \mathrm{Ni}\end{array}$ \\
\hline
\end{tabular}


TABLE I. (continued)

THE EFFECT OF COMPOSITION ON HE/SCC SUSCEPTIBILITY

\begin{tabular}{|c|c|c|c|c|c|c|}
\hline Element & Alloy & Environment & $\begin{array}{l}\text { General } \\
\text { Susceptibility }\end{array}$ & Threshold & $\begin{array}{l}\text { Crack } \\
\text { Growth }\end{array}$ & Comments \\
\hline $\mathrm{Cr}$ & $\begin{array}{l}4340 \\
<2 \% \mathrm{Cr} \\
\mathrm{Fe}-0.3 \mathrm{C} \\
2-12 \% \mathrm{Cr} \\
\gamma-S S\end{array}$ & $\begin{array}{l}\mathrm{H}_{2} \text { gas } \\
3.5 \% \mathrm{NaCl} \\
42 \% \mathrm{MgCl}_{2}\end{array}$ & $\begin{array}{l}\text { no effect } \\
\text { no effect } \\
\text { decreases }\end{array}$ & $\begin{array}{c}\text { no effect } \\
\text { no effect } \\
-\end{array}$ & $\begin{array}{l}- \\
-\end{array}$ & $\begin{array}{l}(18) \\
(17) \\
\text { a minimum in benefit } \\
\text { with } 15-18 \% \mathrm{Cr}(3)\end{array}$ \\
\hline Mn & $\begin{array}{l}4340 \\
\mathrm{Fe}-0.3 \mathrm{C} \\
\gamma-\mathrm{SS}\end{array}$ & $\begin{array}{l}\mathrm{NaCl} \text { sol' } \mathrm{n} \text {. } \\
\text { cathodically charged } \\
\mathrm{H}_{2} \text { gas }\end{array}$ & increases & decreases & - & $\begin{array}{l}\text { substantially } \\
\text { decreases up to } 3 \% \\
\operatorname{Mn}(3,17,18)\end{array}$ \\
\hline \multirow[t]{2}{*}{ Si } & $\begin{array}{l}4340,300 M \\
\text { HY } 130\end{array}$ & $\begin{array}{l}\mathrm{NaCl} \text { sol' } n \text {, water } \\
\mathrm{H}_{2} \text { gas }\end{array}$ & $\begin{array}{l}\text { decreases } \\
\text { increases }\end{array}$ & $\begin{array}{l}\text { no change } \\
\text { decreases }\end{array}$ & decreases & $\begin{array}{l}(25) \\
\text { susceptibility in- } \\
\text { creases when Si pro- } \\
\text { motes grain boundary } \\
\text { segregation. }(6)\end{array}$ \\
\hline & $\begin{array}{l}r-S S \\
\geq 4 \% S i\end{array}$ & $42 \% \mathrm{MgCl}_{2}$ & decreases & - & - & $\begin{array}{l}\text { stabilizes } \delta \text { ferrite } \\
\text { (24) }\end{array}$ \\
\hline Mo & $\begin{array}{l}\mathrm{Fe}-0.3 \mathrm{C} \\
4130 \\
\mathrm{Fe}-18 \mathrm{Cr} \\
10-25 \% \mathrm{Ni}\end{array}$ & $\begin{array}{l}\mathrm{NaCl} \text { sol'n } \\
\text { cathodically charged } \\
22 \% \mathrm{NaCl}\end{array}$ & $\begin{array}{l}\text { little effect } \\
\text { decreases } \\
\text { decreases }\end{array}$ & $\begin{array}{l}\text { little effect } \\
\text { decreases } \\
\text { increases }\end{array}$ & $\begin{array}{l}- \\
-\end{array}$ & $\begin{array}{l}(17) \\
(26) \\
\text { no susceptibility } \\
\text { with } 5 \% \text { Mo (22) }\end{array}$ \\
\hline . & $\begin{array}{l}\gamma-\mathrm{SS} \\
\leq 1.5 \% \mathrm{Mo} \\
\overline{2} .5 \% \mathrm{Mo}\end{array}$ & $\begin{array}{l}42 \% \mathrm{MgCl}_{2} \\
42 \% \mathrm{MgCl}_{2}\end{array}$ & $\begin{array}{l}\text { variable } \\
\text { decreases }\end{array}$ & - & - & $\begin{array}{l}(3) \\
(24)\end{array}$ \\
\hline
\end{tabular}


TABLE I. (continued)

THE EFFECT OF COMPOSITION ON HE/SCC SUSCEPTIBILITY

\begin{tabular}{|c|c|c|c|c|c|c|}
\hline Element & Alloy & Environment & $\begin{array}{l}\text { General } \\
\text { Susceptibility }\end{array}$ & Threshold & $\begin{array}{l}\text { Crack } \\
\text { Growth }\end{array}$ & Comments \\
\hline P\&S & $\begin{array}{l}4340 \text { type } \\
\geq 0.004 \%\end{array}$ & $\mathrm{H}_{2}$ gas & increases & decreases & - & $\begin{array}{l}\text { susceptibility in- } \\
\text { creases if } P \text { or } S \text { are } \\
\text { on grain boundaries } \\
(24,27)\end{array}$ \\
\hline & $\begin{array}{l}\gamma-S S \\
\geq 0.004 \% p\end{array}$ & $42 \% \mathrm{MaCl}_{2}$ & increases & - & - & $\begin{array}{l}\text { susceptibility in- } \\
\text { creases if } P \text { or } S \text {-are } \\
\text { on grain boundaries } \\
(24)\end{array}$ \\
\hline$N$ & $\begin{array}{l}\mathrm{Fe}-18 \mathrm{Cr}- \\
18 \mathrm{Ni} \\
>0.01 \% \mathrm{~N} \\
309 \mathrm{~S} \\
21-6-9\end{array}$ & $\begin{array}{l}42 \% \mathrm{MgCl}_{2} \\
\text { Cathodically charged } \\
\mathrm{H}_{2} \text { gas }\end{array}$ & $\begin{array}{l}\text { increases } \\
\text { increases }\end{array}$ & - & - & $\begin{array}{l}(24,28,29) \\
N \text { promotes planar slip } \\
(3)\end{array}$ \\
\hline
\end{tabular}




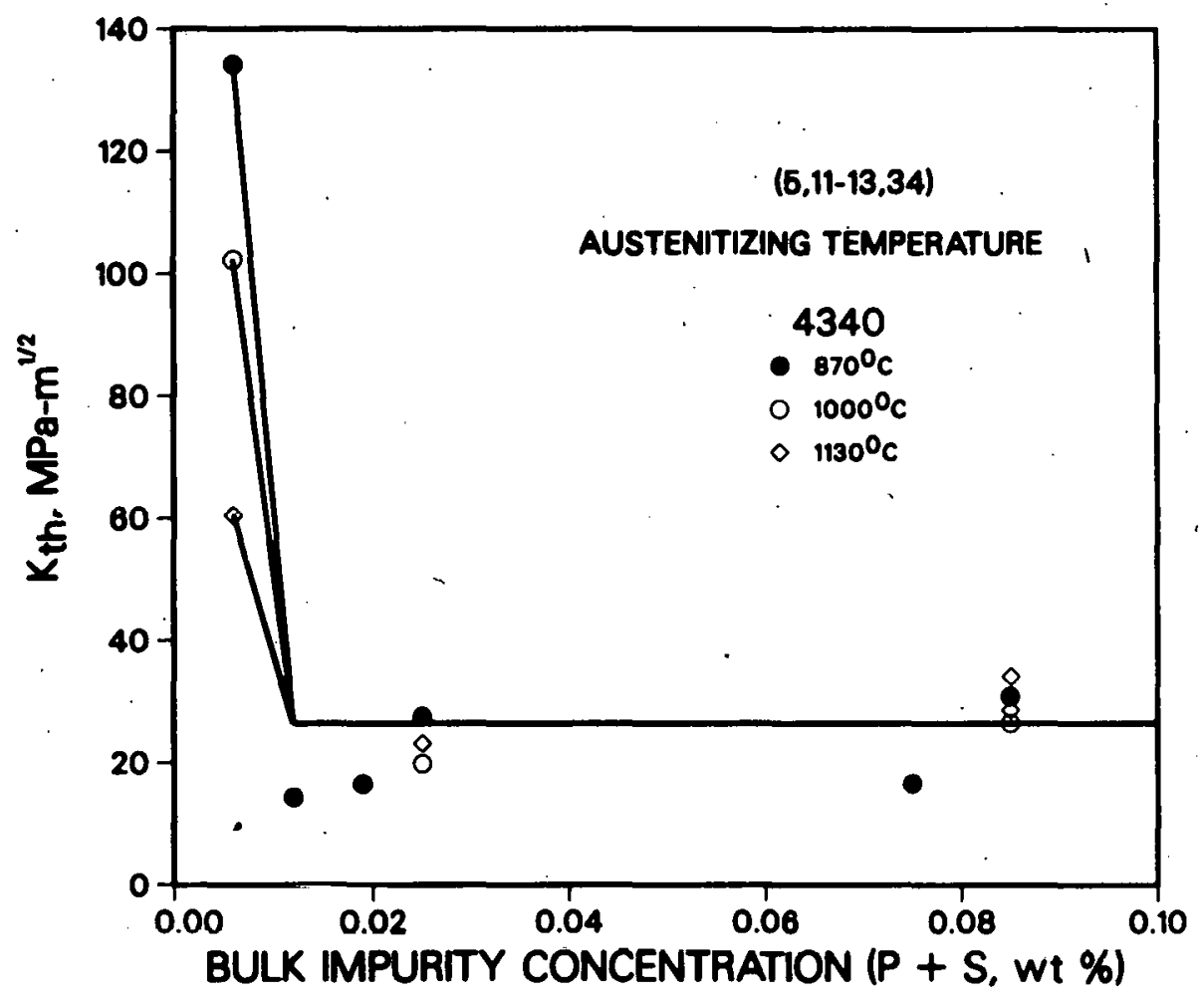

Figure 1. The effect of bulk impurity concentration on hydrogen-induced thresholds for commercial 4340 . 
Boron provides an interesting contrast. Small additions of boron to Fe-12Mn prevents intergranular failure by interfering with ferrite nucleation at prior austenite grain boundaries. The result is a significant increase in low temperature toughness. ${ }^{9}$ Recent work by Brooks et al.40,41 on A-286 and JBK shows that boron does not have a significant effect on $H E$ susceptibility as measured by tensile ductility. However, boron's influence on environmental susceptibility to cracking has not been determined.

\section{Microstructure}

A change in microstructure can change an alloy's susceptibility to hydrogen embrittlement and stress corrosion cracking. Microstructurally, $\mathrm{HE} / \mathrm{SCC}$ susceptibility generally increases in the following order for bCC steels: lower bainite, quench and tempered martensite or bainite, pearlite and ferrite, spherodized structures and martensite. ${ }^{4}, 42$. This ranking can be modified by interactions between alloying elements, tempering treatments, grain size and environment. 1,3

Studies on the susceptibility of austenitic stainless steels and superalloys to environmentally-induced crack growth are sparse and confined primarily to 304 and 316 stainless steels. $30,43-45$ As in bcc steels, the susceptibility of fcc alloys can be altered by microstructural/heattreatment/environmental interactions. For example, environmental cracking in 304 stainless steel is associated with martensite formation in hydrogen gas and after cathodic charging. However, disagreement exists as to whether martensite is associated with cracking in $\mathrm{MgCl}_{2} \cdot 30,43$ Disagreement also exists over the role of hydrogen in stress-induced martensite formation. One study ${ }^{46}$ shows that hydrogen assists martensite formation in $304 \mathrm{~L}$ whereas another study ${ }^{4}$ finds it does not.

Most work on HE/SCC susceptibility of these fCc alloys is in terms of RA 10ss. 34,48 Rhodes and Thompson 48 show for a number of austenitic stainless steels and superalloys that RA loss is caused by hydrogen-induced acceleration of ductile fracture related to precipitate size and coherency. small, cohcrent precipitates lead to increased environmental susceptibil1ty. This is difficult to correlate with slow crack growth in these alloys which occurs by intergranular failure. ${ }^{49}$ These studies highlight the difficulty in determining environmental susceptibility from dynamic test results.

The resistance of austenitic stainless steels and superalloys to environmental cracking has led to their use for critical components in very aggressive environments. However, serious problems may be encountered when these materials contain welds. The weld material and heat affected zone have different microstructures, impurity concentrations and strength levels, which are more susceptible to environmental cracking than the parent material. 50-54 Studies on the susceptibility of weids in these materials has been confined primarily to aqueous environments though some work has been done in hydrogen gas. 53,54 Further study is required in environments where welds could pose problems. 
The effect of grain size on $\mathrm{HE} / \mathrm{SCC}$ is not well-defined. A number of studies $11-13$ show that increasing grain size is detrimental to susceptibility whereas at least one study 5 shows it to be beneficial. Commercial 4340 is the most thoroughly studied alloy for $\mathrm{HE} / \mathrm{SCC}$ effects. Figure 2 shows the effect of grain size on fracture toughness for this material.55,56 Al though the austenitizing temperature treatment to increase the grain size decreases the fracture stress or strain, the increase in fracture distance is more important. (When fracture strain controls, the fracture distance is indirectly related to the grain size). 55,56 As a result, fracture toughness increases with increasing grain size. For high strength steels such as 4340 , an increase in fracture toughness is paralled by a decrease in Charpy $V$-notch (CVN) energy $11,44,45$ as shown in Figure 3 . This paradox is due to a crack tip radius effect. For fracture ahead of a sharp crack, as in a fracture toughness test, the maximum stress or strain must exceed the fracture stress or strain over a microstructurally characteristic distance. Ahead of a blunt notch, as in a Charpy test, the maximum stress is close to the elastic-plastic boundary, which is beyond the characteristic fracture distance. ${ }^{56}$ Impact toughness is then controlled by just the fracture stress or strain, which varies with austenitizing temperature.

Hydrogen-induced threshold stress intensity exhibits a grain size behavior opposite to fracture toughness as shown in Figure $4.5,11-13,34$ In a high purity 4340 - type steel, I thresholds decrease substantially as grain size increases. Fracture occurred by cleavage, ductile rupture and some intergranular failure in these samples. Commercial 4340 steels $s^{5}, 11-13,34$ exhibit thresholds considerably lower than the high purity alloy with little effect of grain size. Only the data from Gerberich et al.5 show a slight increase in threshold value with increasing grain size. Fracture occurred intergranularly in all commercial 4340 steels.

There are three possible explanations for the observed grain size effects: (1) a plastic zone size/grain size relationship, (2) a difference in characteristic fracture distance between different environments or (3) a grain size effect on grain boundary impurity segregation. The studies by Gerberich et al.5,34 find that, at grain sizes of $20 \mu \mathrm{m}$ or less, the plastic zone size is greater than the grain size. Thresholds corresponding to these grain sizes are relatively constant. When the plastic zone size is less than the grain size, greater applied stresses are required to achieve the critical hydrogen concentration for fracture over the characteristic fracture distance, the grain size. 5 . This indicates that the characteristic fracture distance differs between the two plastic zone size/grain size conditions.

Recent evidence ${ }^{8}, 57$ suggests that the fracture initiation site and the characteristic fracture distance differ between external and internal hydrogen environments for bcc steels. Though no tests have been conducted, this may also be true for fcc steels. Fracture caused by internal hydrogen occurs below the crack tip or notch root and is governed by the triaxial stress state. Failure in external hydrogen environments occurs at the 


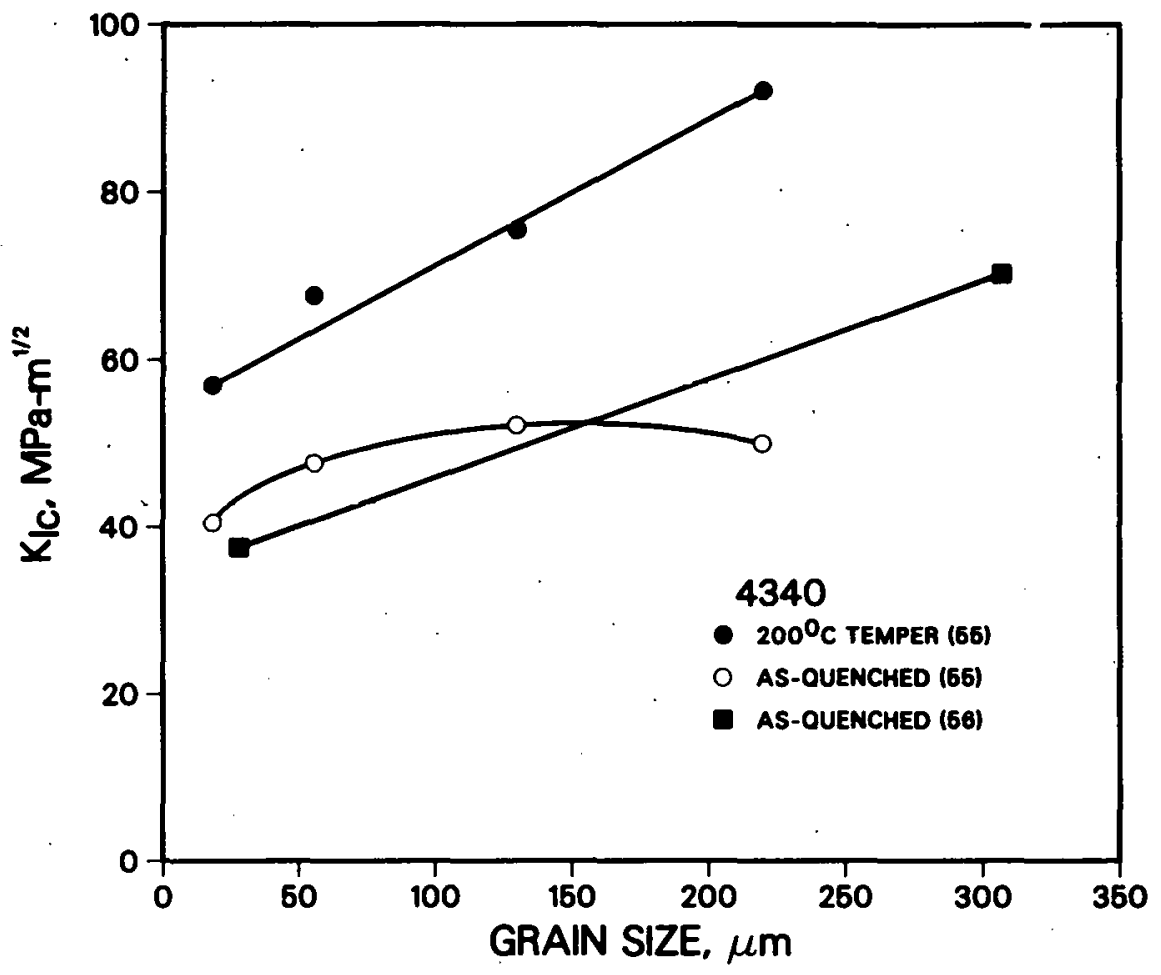

Figure 2. The relationship of grain size to fracture toughness for commercial 4340 . 


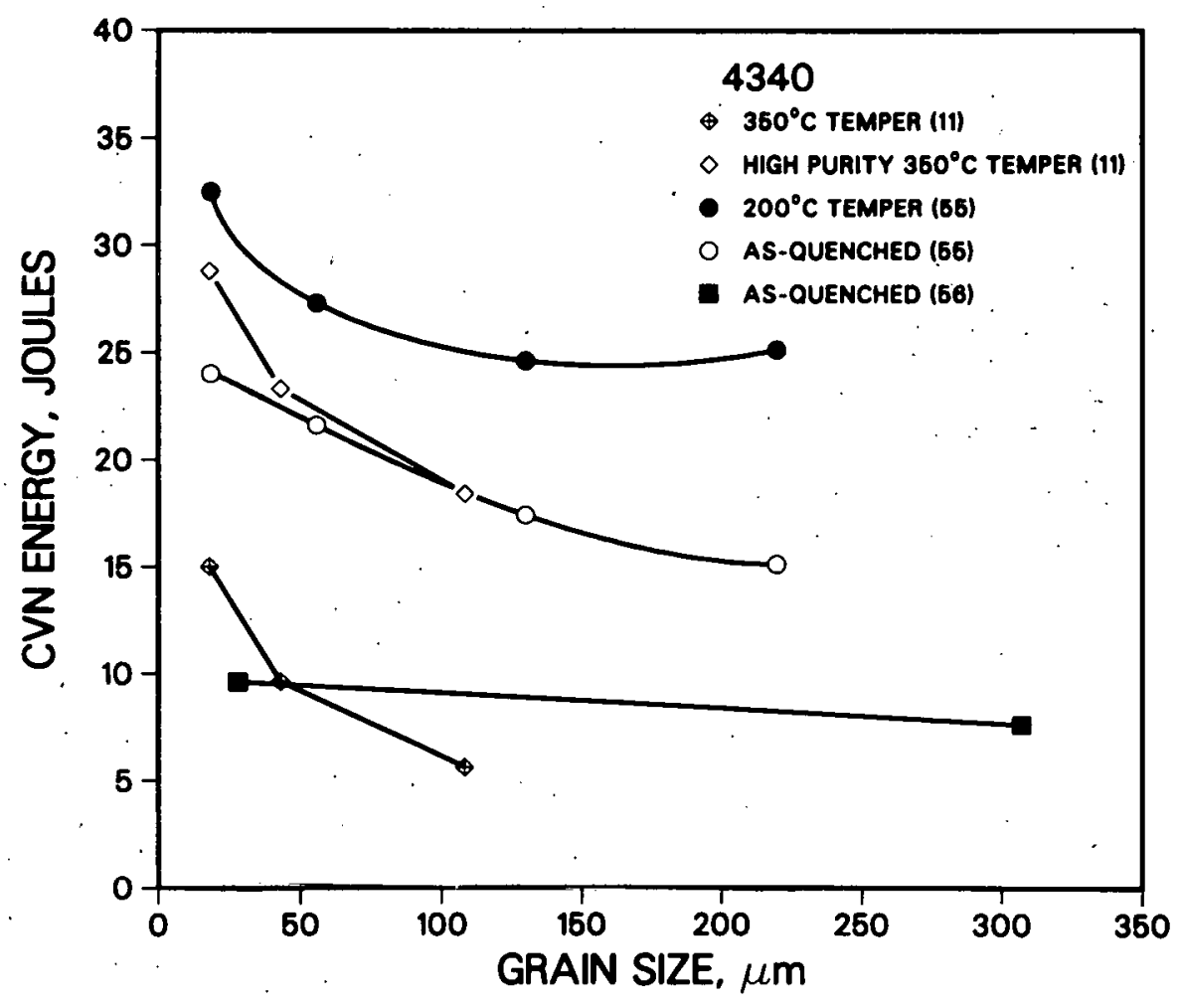

Figure 3. The relationship of 4340 Charpy $V$-notch (CVN) energy to grain size. 


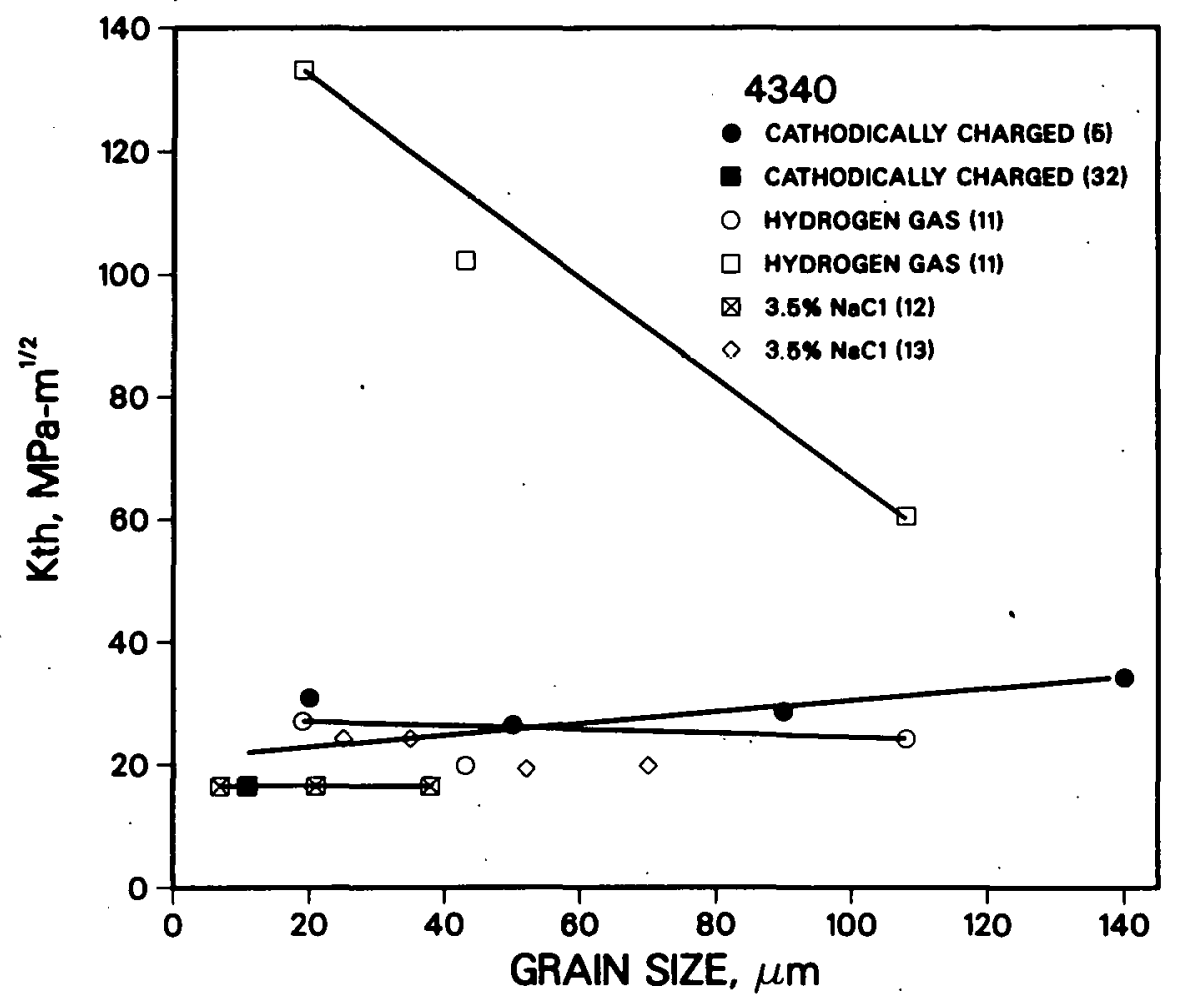

Figure 4. The effect of grain size on hydrogeninduced thresholds in various hydrogen environments for commercial 4340 . 
sample surface and is governed by the maximum tensile stress. ${ }^{8,57}$ The characteristic fracture distance for internal hydrogen failure, which appears to be the grain size, may not hold for external hydrogen failures. This may be further enhanced by grain boundary segregation of impurity elements which enhance hydrogen generation and absorption. 9 Though impurity element concentration varies significantly in the commercial 4340 steels, there is little variation in hydrogen-induced thresholds. However, the high purity 4340 - type alloy exhibits substantially greater threshold values. It is recognized that temper (grain boundary impurity segregation) and hydrogen embrittlement are analogous. ${ }^{4}$ However, whether hydrogen acts as a metalloid impurity, adding its effects, or causes fracture along crack paths sensitized by impurity segregation is unknown.6-8

A plot of hydrogen-induced thresholds versus bulk impurity concentration, as in Figure 1 , shows that thresholds reach a lower limiting value at a bulk impurity concentration near 0.01 weight percent. This does not provide definitive results. It is generally recognized that an increase in grain size reduces grain boundary area and increases the grain boundary impurity concentration. ${ }^{4}, 35$ An estimate of the relative grain boundary impurity concentrations from several studies $5,11,58$ on 4340 versus hydrogen-induced thresholds is shown in Figure 5.* At low grain boundary impurity concentrations, a small change in impurity content causes a significant change in thresholds values. A lower limiting threshold value occurs with a change in fracture from cleavage and ductile rupture to intergranular failure as grain boundary impurity concentration increases. From calculations of hydrogen concentration, 58 more hydrogen is required for failure as impurity concentrations decrease and thresholds increase. The existance of a lower limiting threshold value, irrespective of grain boundary impurity concentration, indicates hydrogen and impurity effects are not additive, at least above a certain concentration. However, some studies ${ }^{6}, 33$ show otherwise.

The effect of grain boundary impurity segregation, determined by the method described for thresholds ${ }_{55}$ on $\mathrm{CVN}$ energy and fracture modes is shown in Figure 6 for 4340 steels. $11,55,56$ At low impurity concentrations, CVN energies are high with fracture occurring by microvoid coalescence. CVN energies decrease rapidly as impurity concentration increases with a change in fracture to intergranular failure. The change in fracture occurs at a

*The estimates of relative grain boundary impurity concentrations are made as follows: (1) Assume a cube of unit volume $V$ comprised of small cubes with side $d$, the desired grain size. (2) Determine the grain boundary area in $V$ from the number of small cubes $\left(V / d^{3}\right)$ times the grain boundary area per small cube $\left(6 d^{2}\right)$ divided by 2 to eliminate common sides. (Ag.b. = $3 \mathrm{~V} / \mathrm{d}$ ). (3) Assume all impurity elements partition between the grain boundaries and the lattice in a constant ratio $R$ for a grain size of $10 \mu \mathrm{m}$. The grain boundary impurity concentration for a grain size of $10 \mu \mathrm{m}$ is then $R B$, where $B$ is the bulk impurity concentration. (4) Normalize the change in grain boundary area with grain size to a grain size of $10 \mu \mathrm{m},(10 / \mathrm{d})$. Allow the relative grain boundary impurity concentration to vary inversely with grain boundary area. The relative grain boundary impurity concentration is then given by $(\mathrm{RBd} / 10)$. 


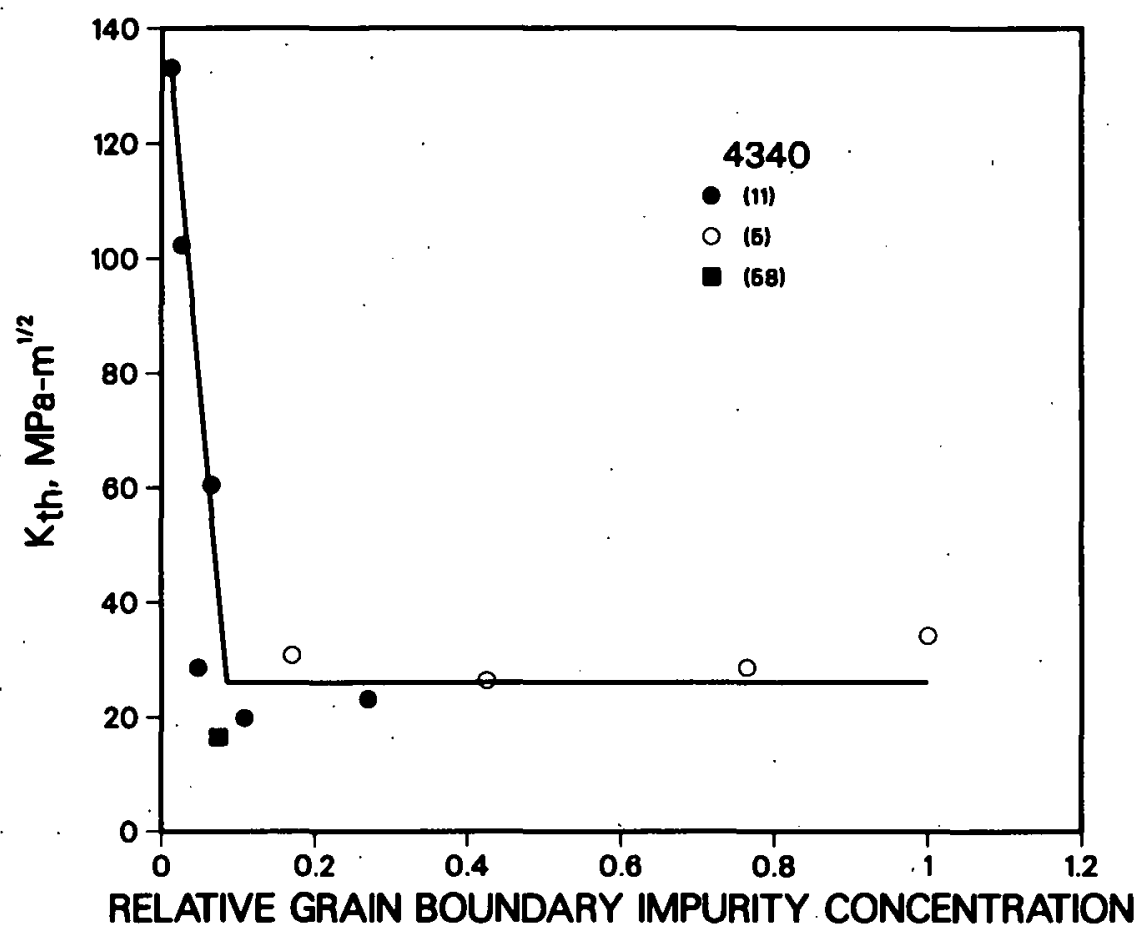

Figure 5. The effect of grain boundary impurity concentration on hydrogen-induced thresholds in commercial 4340 . 


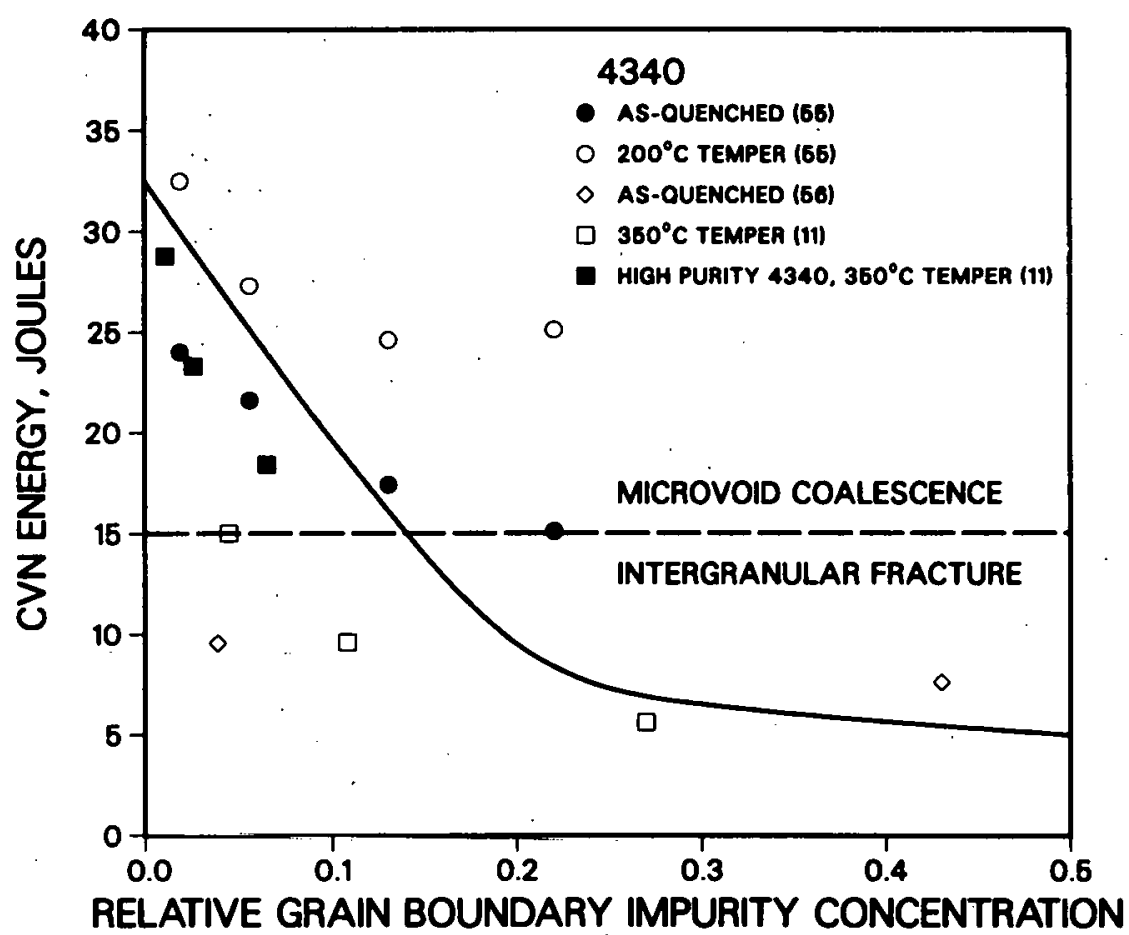

Figure 6. As grain boundary impurity concentration increases, CVN energy decreases. At a low grain boundary concentration, fracture changes from microvoid coalescence to intergranular failure. 
grain boundary impurity concentration similar to the onset of intergranular failure associated with hydrogen-induced thresholds. This suggests that grain boundary impurity segregation sensitizes a preferred crack path for HE/SCC fracture.

Studies need to be conducted to accurately define the relationship between hydrogen embrittlement, grain size and impurity concentration. Determination of the grain size effect requires that the grain boundary impurity concentration and yield strength be controlled while varying the grain size and hydrogen concentration. Different environments need to be studied to produce different fracture initiation sites and fracture distances. Also, grain boundary impurities may promote hydrogen generation and absorption in some environments and possibly. change the character of the grain boundary.

\section{Environmental Effects}

Disagreement has persisted for some time over the mechanisms involved in internal and external environmental embrittlement. Studies have been conducted in water, 59 gaseous hydrogen, 60.66 salt water, 4,22 hot salt solutions ${ }^{43}, 45$ and internal hydrogen from cathodic charging. ${ }^{34,58,65}$ Regardless of environment, there is a striking similarity of fracture modes. Threshold values and crack growth kinetics can change significantly with a change in environment for the same material. As discussed in the previous section, a difference in fracture initiation site and characteristic fracture distance between internal and external environments exists. Also, the rate-controlling process may differ between environments.

\section{Hydrogen Gas}

Oriani and Josephic ${ }^{61}, 62$ studied the effect of hydrogen gas pressure on the threshold stress intensity necessary to initiate crack growth in a 4340 steel. Over the range of pressures from $10^{-5}$ to $10^{-1} \mathrm{MPa}$, thresholds vary logarithmically with pressure. Other studies ${ }^{63}, 65,66$ show similar behavior up to pressures of one MPa as shown in Figure 7. The wide variance in the data could stem from yield strength, ${ }^{58}$ grain size, 5 impurity segregation ${ }^{31}$ or surface contamination effects. ${ }^{62}$ Thresholds increase as yield strength decreases and are related to the yield strength indirectly through an elastic approximation as follows

$$
K_{T H}=\frac{3(2 \pi r)^{1 / 2} R T}{2(1+\nu) \bar{V}_{H}} \text { en }\left(C_{C r} / C_{0}\right)
$$




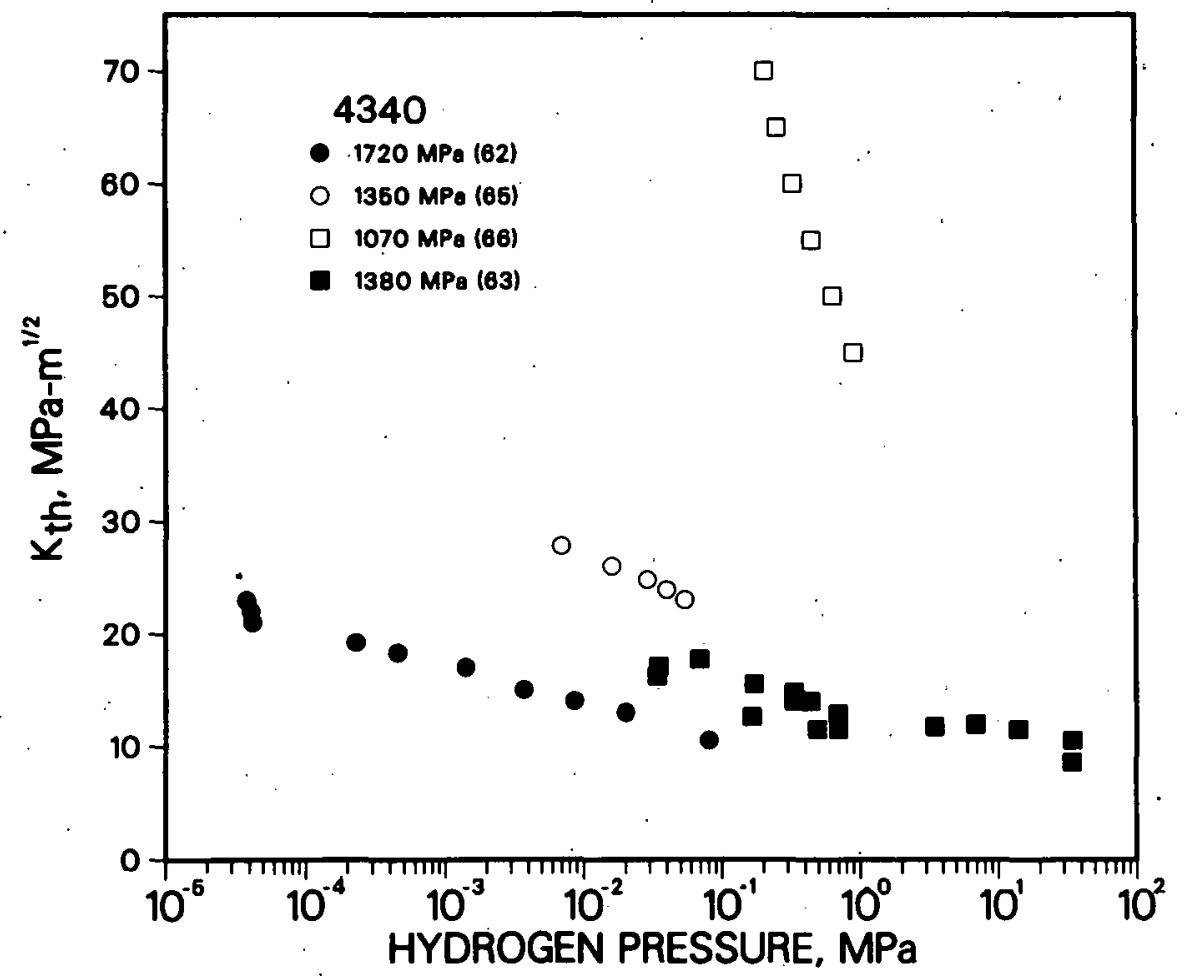

Figure 7. The influence of hydrogen pressure on threshold behavior for commercial 4340 with yield strengths ranging from 1070 to $1720 \mathrm{MPa}$. 
where $C_{c r}$ and $C_{0}$ are the critical and initial hydrogen concentrations respectively, $C_{c r} / C_{0} \simeq B / \sigma y s, r$ is the fracture distance and $\nabla_{H}$ is the partial molar volume of hydrogen. The data shown in Figure 7 , normalized with respect to $\ln (\beta / \sigma y s)$ with $\beta=3180 \mathrm{MPa}{ }^{58}$, are shown in Figure 8 . There is good agreement between the high strength data of Oriani and Josephic 62 and Walter and Chandler ${ }^{63}$.

Austenitic stainless steels and superalloys exhibit similar threshold behavior with respect to yield stress as bcc steels 67 , as shown in Figure 9 , but require more aggressive conditions. Furthermore, the elastic approximation given by equation (1) is not valid as the partial molar volume of hydrogen in these materials is smal1.68 A more accurate description of hydrogen-induced thresholds, applicable for both bcc and fcc alloys incorporates the effect of hydrogen on fracture stress as follows ${ }^{69}$

$$
\sigma_{f}^{\star}=\sigma_{f}^{\star}-\alpha C_{H}
$$

where ${ }^{42,66}$

$$
C_{H}=A p{ }^{1 / 2} \exp \left[\left(-H_{s}+\sigma_{h} V_{H}+H_{b}\right) / R T\right]
$$

Here $\sigma_{f}{ }^{\star}$ is the fracture stress without hydrogen, $p$ is the hydrogen pressure, $H_{s}$ is the enthalpy of solution, $H_{b}$ is the binding enthalpy and $\sigma_{h} V_{H}$ is the hydrostatic stress term. Also, the pre-exponential term, $A$, probably depends on the yield strength. A complete set of values for these terms is not available but equations (2) and (3) predict qualitatively correct hehavior.

Thresholds for high strength 4340 become independent of hydrogen pressures near one MPa. Similar behavior at higher pressures is observed in austenitic stainless steels, intermediate strength ferritic steels and IN718.63,64,67 It is proposed that the concentration of hydrogen remains constant at high pressures, controlled by a surface reaction rather than the pressure. ${ }^{63} \mathrm{~A}$ number of other explanations exist. At high pressures Sievert's Law may not be obeyed. 70 Stowell et al. 70 show that thresholds depend on both the enp and $p$ and modify Sievert's Law to yield this dependence. Thresholds predicted from a model using this modification still deviate from experimental results. ${ }^{70}$. Another possibility arises fromthe results of mechanical property tests in high pressure environments. $71-73$ Only a small change in yield strenath is observed with increased pressure whereas the fracture stress for intergranular failure above the DBTT increases linearly with superimposed hydrostatic pressure. 73 High pressure may therefore play a role in establishing thresholds through the fracture stress. Perra 57 proposes the most probable explanation. The solubility and diffusivity of hydrogen are influenced by the trapping of hydrogen at grain boundaries, dislocations and precipitates. ${ }^{1}, 2$ These traps may be hydrogeninduced fracture sites ${ }^{74}$ which saturate at high pressures resulting in thresholds independent of pressure. 


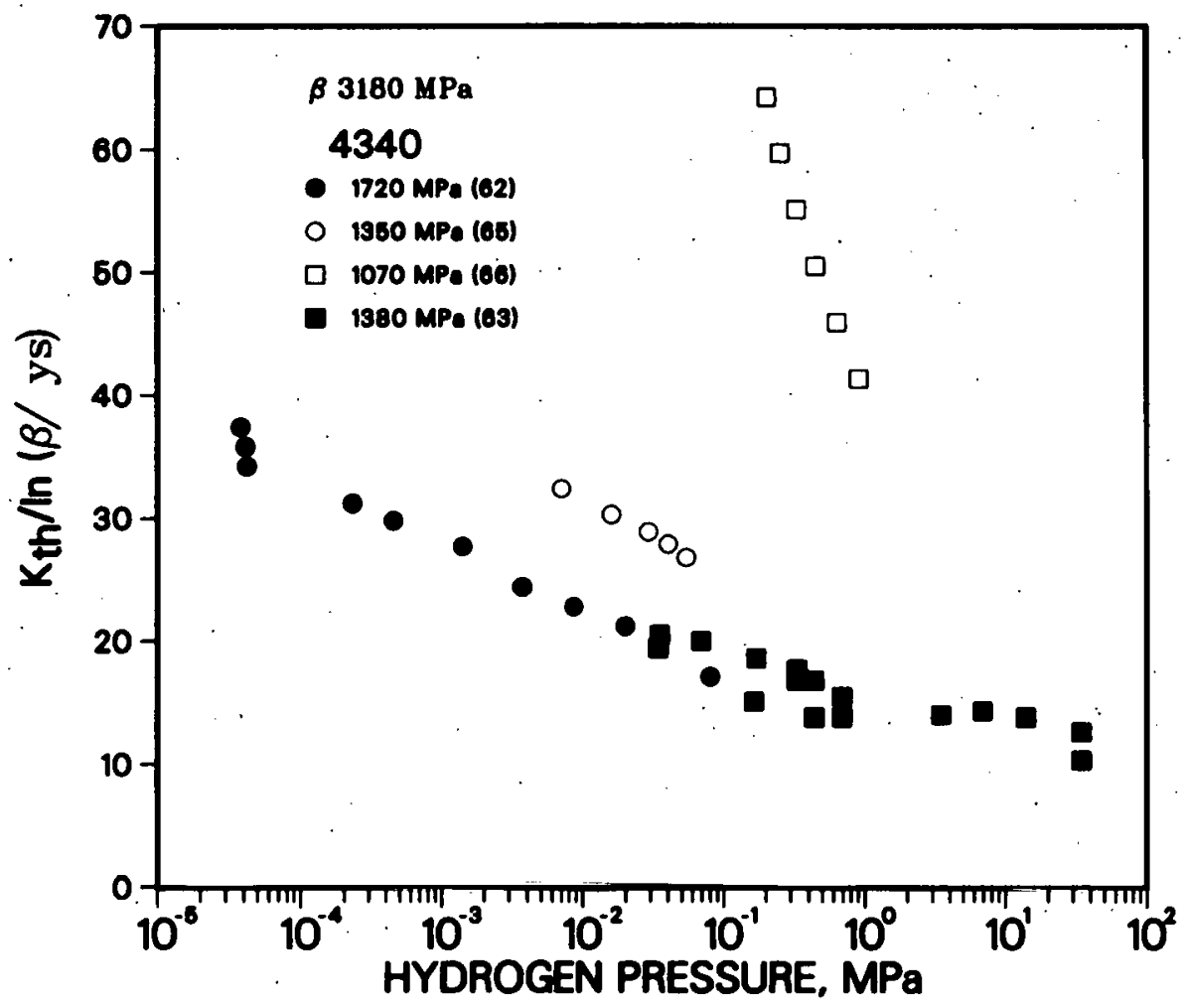

Figure 8. Thresholds for high yield strength materials normalized on yield strength. 


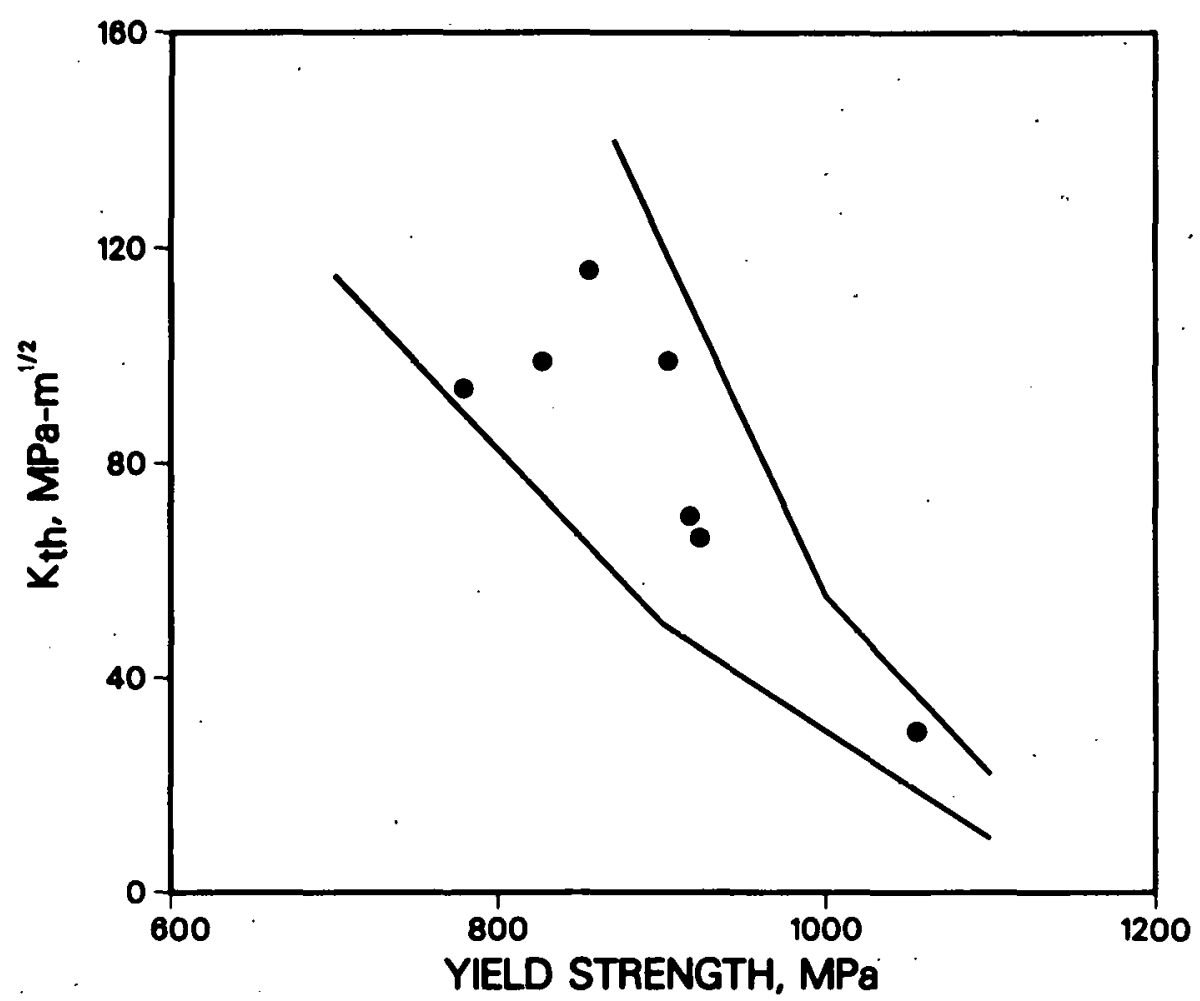

Figure.9. Austentic stainless steel and superalloy thresholds follow a common plot with yield stress. The data was obtained in hydrogen gas at pressures of 100 and $200 \mathrm{MPa}$. 
Studies on the effect of temperature on thresholds are sparse with measurements confined primarily to pressures less than two atmospheres. In maraging steels at low temperatures, ${ }^{60}$ thresholds approach a lower limiting value. Near ambient temperatures, a transition occurs with threshold values increasing rapidly as temperature increases. The temperature at which this transition occurs depends on both the yield strength and the pressure.

Crack growth rates also vary with temperature and pressure. Near ambient pressures and temperatures of $300 \mathrm{~K}$ and below, crack growth rates increase as temperature increases. $59,60,75$ The rate-controlining process in this region is the diffusion of hydrogen through the lattice. At very low pressures, 4340 crack growth rates in $\mathrm{H}_{2} \mathrm{~S}^{75}$ are proportional to $\mathrm{pT}^{\mathrm{l} / 2}$. The rate of hydrogen transport from the environment to the crack tip is believed to control crack growth. Crack growth rate dependencies and the rate-controlling processes for crack growth are not known for austenitic stainless steels and superalloys.

Crack growth rates exhibit a $p^{3 / 2}$ to $p^{2}$ dependency over the narrow temperature range where thresholds rapidly approach the fracture toughness value. 42,60 This appears to be a surface effect. If hydrogen is predissociated by an electrical discharge, the transition behavior disappears and crack growth rates continue to increase with temperature. This suggests that crack growth is controlled by adsorption 60,76 with the fractional surface coverage of adsorbed hydrogen decreasing as temperature increases above a critical value.

Internal Hydrogen

Processes such as cleaning or plating and some environments may introduce hydrogen into a material before it is stressed. Experimentally, hydrogen can be easily introduced into samples by cathodic or gas-phase charging but few studies on thresholds and crack growth kinetics have been done. $5,34,58,65$ Gerberich et al. 65 show that thresholds from internal hydrogen exhibit the same yield strength dependency as external hydrogeninduced thresholds. A threshold model based on a plastic stress field approach accurately predicts thresholds for varying yield strengths in both internal and external environments. It also predicts the proper trend with temperature below $~ 300 \mathrm{~K}$ for thresholds in a gaseous hydrogen environment. However, thresholds from internal hydrogen concentrations as a function of temperature are not available for comparison.

Hydrogen-induced crack growth rates for 4340 from both internal and external hydrogen tests show a direct dependence on yield strength and an inverse dependence on grain size. ${ }^{5}, 12$ These results are in agreement with rates predicted by short-term diffusion kinetics for bcc steels when hydrogen diffusivity remains constant. However, predicted rates to not agree with maraging steel data. ${ }^{60}$ Internal hydrogen threshold and crack growth rate data are needed not only to determine temperature response, particularly at high temperatures, but also to determine hydrogen concentration and fracture distance dependencies. 
Stress Corrosion Cracking - Aqueous Environments

Stress corrosion cracking in aqueous solutions, especially acidic solutions, is common to most alloy systems. It is the result of both a corrosion reaction and an applied stress. ${ }^{77}$ There are a number of similarities between hydrogen embrittlement and stress corrosion cracking. Under both conditions, susceptibility increases with increasing yield strength and the degree of planar slip. Stress corrosion processes are not well understood but are usually described in terms of a dissolution mechanism and/or hydrogen embrittlement. An anodic dissolution reaction converts the metal to dissolved cations or a corrosion product $f i l m$ which results in active path cracking and hydrogen generation. Cracking can also proceed from absorbed hydrogen produced at a local cathode. 10

Conflicting test results complicate mechanism determination. High strength steels tested in water fail by hydrogen-induced cracking. 59 In $18 \mathrm{Ni}(250)$ maraging steel, ${ }^{10}$ open circuit and anodic polarization results in active path, intergranular cracking whereas cathodic polarization results in hydrogen-induced cleavage. However, crack tip conditions are quite different than indicated by bulk electrolyte or smooth surface measurements under anodic and cathodic polarization. Both metal dissolution and hydrogen evolution may occur at the crack tip regardless of electrochemical potential. 10,78

Green et al. ${ }^{79}$ use mode I. (tension) and mode III (torsion) loadings to distinguish between hydrogen embrittlement and anodic dissolution. Hydrogen diffusion is driven by the hydrostatic stress component of the stress tensor under mode I loading, whereas, the hydrostatic stress component is absent in mode III loadings. This is used to identify the cracking mechanism. For example, thresholds are significantly reduced in Ti-8A1-1Mo from fracture toughness values during mode I loading in an aqueous solution while little effect is observed under mode III loading; the result of hydrogen-induced crackina. However, $\alpha$-brass fractures readily under both loading modes in ammonia; the result of anodic dissolution.

Hydrogen embrittlement is generally regarded as the responsible mechanism for subcritical cracking in high strength steels. Even though one mechariisil may be responstble for cracking, crack growth rates can vary significantly between different environments. The activation energy of $18.9 \mathrm{~kJ} /$ mole for 4340 tested in hydrogen gas corresponds to a rate-controlling process of hydrogen diffusion through the 1attice. ${ }^{59}$ In water, an activation energy of $33.5 \mathrm{~kJ} / \mathrm{mole}$ is obtained. This corresponds to the reaction of water with the sample surface, which forms an oxide and produces hydrogen. 59

Grain boundary impurities can enhance susceptibility in aqueous solutions. The impurities may catalyze anodic dissolution ${ }^{9}, 10$ or increase the number of uncombined adatoms at the grain boundaries which have a high probability of absorption. 10 Either process may be accompanied by an aiteration of local grain boundary structure or chemistry and change susceptibility and crack growth behavior. 7,80 
Hydrogen Transport

There exists some disagreement over the exact roles of bulk lattice diffusion and dislocation transport, where hydrogen is identified as the damaging species for environmentally-induced cracking. Bulk lattice diffusion has been identified as the rate-controlling process for hydrogeninduced cracking in a number of cases. $25,59,60$ However, dislocation transport is invoked as an explanation for hydrogen outgassing during plastic deformation and greater hydrogen penetration and accumulation than possible through diffusive transport. 84,85 Determination of hydrogen transport mechanisms is complicated by hydrogen's interaction with impurities, dislocations, and interfaces. ${ }^{79}, 80$ These interactions alter apparent diffusivities and susceptibility to hydrogen embrittlement. ${ }^{4}, 23$

\section{Dislocation Transport}

Donovan 82 observed enhanced hydrogen evolution from a variety of materials during plastic deformation. Hydrogen is released suddenly at the yield stress, more slowly during further deformation and finally exhibits a burst at failure. This effect is attributed to the dislocation transport of hydrogen. ${ }^{81}, 82$ Further support is provided by Louthan's $s^{86}$ autoradiographic study on $304 \mathrm{~L}$ stainless steel which found tritium localized on the slip planes.

Tien et a1. 81 and Louthan ${ }^{87}$ determined that a dislocation density of $10^{7} \mathrm{~cm}^{-2}$ in steel requires just $0.1 \mathrm{ppm}$ hydrogen to saturate all dislocation core sites assuming a one-to-one ratio of hydrogen to metal atoms. When the dislocation density is $10^{12} \mathrm{~cm}^{-2}$, dislocations can accomodate $1000 \mathrm{ppm}$. Once a hydrogen atom is trapped by a dislocation, it will be either pinned, move with or break free of the dislocation if the dislocation velocity exceeds a critical value. For a given strain rate, the critical velocity decreases as temperature decreases with an accompanying decrease in hydrogen transport. When dislocation velocity is less than the critical velocity, hydrogen penetration can be quite deep compared to diffusive transport which could account for crack growth rates exceeding those determined by lattice diffusion rates.

\section{Stress-Assisted Diffusion}

West and Louthan ${ }^{88}$ find that dislocation transport of hydrogen is not required for hydrogen embrittlement of austenitic stainless steels. A number of other studies $25,59,60$ reach a similar conclusion. In these studies, the lattice diffusion of hydrogen is identified as the rate-controlling process for hydrogen-induced cracking. Further support comes from Gerberich et al. ${ }^{34}$ who quantitatively correlate crack velocity with shorttime diffusion associated with stress-induced hydrogen migration. Their results are in good agreement with 4340 crack growth data.

Although there is disagreement as to the mechanism of hydrogen transport, it is widely recognized that the hydrostatic stress field at the tip 
of the crack is associated with hydrogen embrittlement. Hydrogen interacts with crack tip stress fields and accumulates in regions of maximum stress. The equilibrium hydrogen concentration in an elastic stress field was derived thermodynamically by Li, Oriani and Darken ${ }^{89}$ and is expressed as follows 58

$$
C_{e}=C_{j} \exp \left(\sigma_{i j} \bar{V}_{H} / 3 R T\right)
$$

Here $\sigma_{j i}$ is the trace of the stress tensor, $C_{0}$ and $C_{e}$ the initial and equilibrium hydrogen concentrations respectively and $V_{H}$ is the partial molar volume of hydrogen in the lattice.

Experimental evidence supporting these results comes from Wriedt and Oriani's work ${ }^{90}$ on $75 \% \mathrm{Pd}-25 \% \mathrm{Ag}$. They show that the equilibrium concentration of hydrogen increases with tensile stress and decreases with compressive stress to within $2.5 \%$ of theoretical predictions.

\section{Experimental Observations}

A comparison of hydrogen-induced cracking behavior under mode I (tension) and mode III (torsion) loadings can reveal the role of dislocation and diffusive transport mechanisms. ${ }^{1}$ Stress-assisted hydrogen diffusion is driven by the pressure tensor while dislocation transport is driven by appropriate shear stress components. Mode I loading has pressure tensor components while mode III does not. Comparative tests 91 show that under mode III loading, a high strength steel is insensitive to hydrogen while under mode I loadings the steel is susceptible to hydrogen-induced cracking. This supports the stress-assisted diffusion mechanism argument.

Swearengen et al. ${ }^{46}$ find that $304 \mathrm{~L}$ is susceptible to hydrogen embrittlement under pure stress corresponding to mode III loads and conclude that hydrogen accelerates ductile fracture by changing rate sensitivity and thereby increasing shear instability. The observations are consistent with the belief that hydrogen is transported by dislocations at ordinary strain rates but that dislocations are free of hydrogen at higher rates. This corresponds with Baskes et al.68 calculations that hydrogen is weakly bound to dislocations in fcc materials. Interestingly, Baskes et al. find that weak pipe diffusion exists along edge dislocations in an fcc lattice. Presentiy, data is insufficient to define the role of dislocation and/or diffusive transport in hydrogen embrittlement.

Hydrogen Diffusivity, Solubility and Partial Molar Volume

When discussing hydrogen embrittlement appropriate hydrogen diffusivities, solubilities and partial molar volumes are required. A change in partial molar volume changes the equilibrium hydrogen concentration in a stress field. Partial molar volumes are usually determined from dilatometric measurements. As discussed by Hirth, 42 partial molar volumes of hydrogen 
for a number of bcc iron and steel alloys range from 1.6 to $2.6 \mathrm{~cm}^{3} / \mathrm{mole}$. The overall average is near $2.0 \mathrm{~cm}^{3} / \mathrm{mole}$. Baskes et al. ${ }^{68}$ calculate that the partial molar volume of hydrogen in austenite is much smaller $1-0.6$ $\mathrm{cm}^{3} / \mathrm{molel}$.

Hydrogen diffusivity and solubility are determined from hydrogen permeation experiments, either by electrochemical ${ }^{92}$ or gas-phase charging ${ }^{93}$ techniques. Gas-phase charging is the preferred method because hydrogen partial pressures fix unambiguously the chemical potential of the charging medium. ${ }^{4}$ Oriani 95 found the following relationship for the solubility of hydrogen in iron.

$$
C_{0}=0.00185 p^{1 / 2} \exp (-3440 / T)
$$

Hirth ${ }^{4} 2$ finds good agreement exists between predicted and measured solubilities in high purity and zone-refined irons. Solubility measurements near room temperature are difficult though, due to strong traps which prevent complete hydrogen outgassing. ${ }^{42}$ Calculations on hydrogen solubility in a crack tip stress field show that solubility increases by a factor of five for bcc iron while no significant change occurs in austenite. ${ }^{68}$ Experimental work is needed in this area as stress field solubility may be the important factor in the resistance of austenitic stainless steels and superalloys to $\mathrm{HE} / \mathrm{SCC}$.

Volkl and Alefeld $d^{96}$ have compiled the results of over forty tests on hydrogen diffusivity in a number of iron and steel alloys. Bounding curves for their data are shown in Figure 10 with some representative data points for three alloys.92,97,98 Hydrogen diffusivities are similar above $150^{\circ} \mathrm{C}$. Near ambient temperatures, the diffusivities vary by more than four orders of magnitude compared to 'pure' diffusion in iron given by the upper curve in this figure. This variation reflects the effects of alloy composition, structure and particularly trapping. 1,42

Trapping

The effect of trapping on the effective diffusivity of hydrogen and on fracture initiation sites is important since trapping affects crack growth kinetics and susceptibility. ${ }^{23}$ A number of trapping sites have been proposed, including microvoids, inclusions, grain boundaries, precepitates, interstitial atoms and vacancies. ${ }^{85}$ Pressouyre and Bernstein ${ }^{23}$, studying trapping strengths in the $\mathrm{Fe}-\mathrm{C}-\mathrm{Ti}$ system find the following relationship between the binding energies for various traps.

$$
E(T i C-H) \gg E(G B-H), E(T i-H), E(\text { dislocation }-H) \gg E(\text { lattice }-H)
$$

Asaoka et al's. ${ }^{85}$ autoradiographic results support these findings. TiC precipitates are irreversible traps which fill first. The other traps are reversible with a dynamic equilibrium existing between hydrogen in these traps and the diffusion of hydrogen through the lattice. ${ }^{23}$ Autoradiography on austenitic stainless steel. shows that there is no enhancement of hydrogen at the grain boundaries with the concentration of hydrogen at defects roughly equivalent to the lattice concentration.99,100 


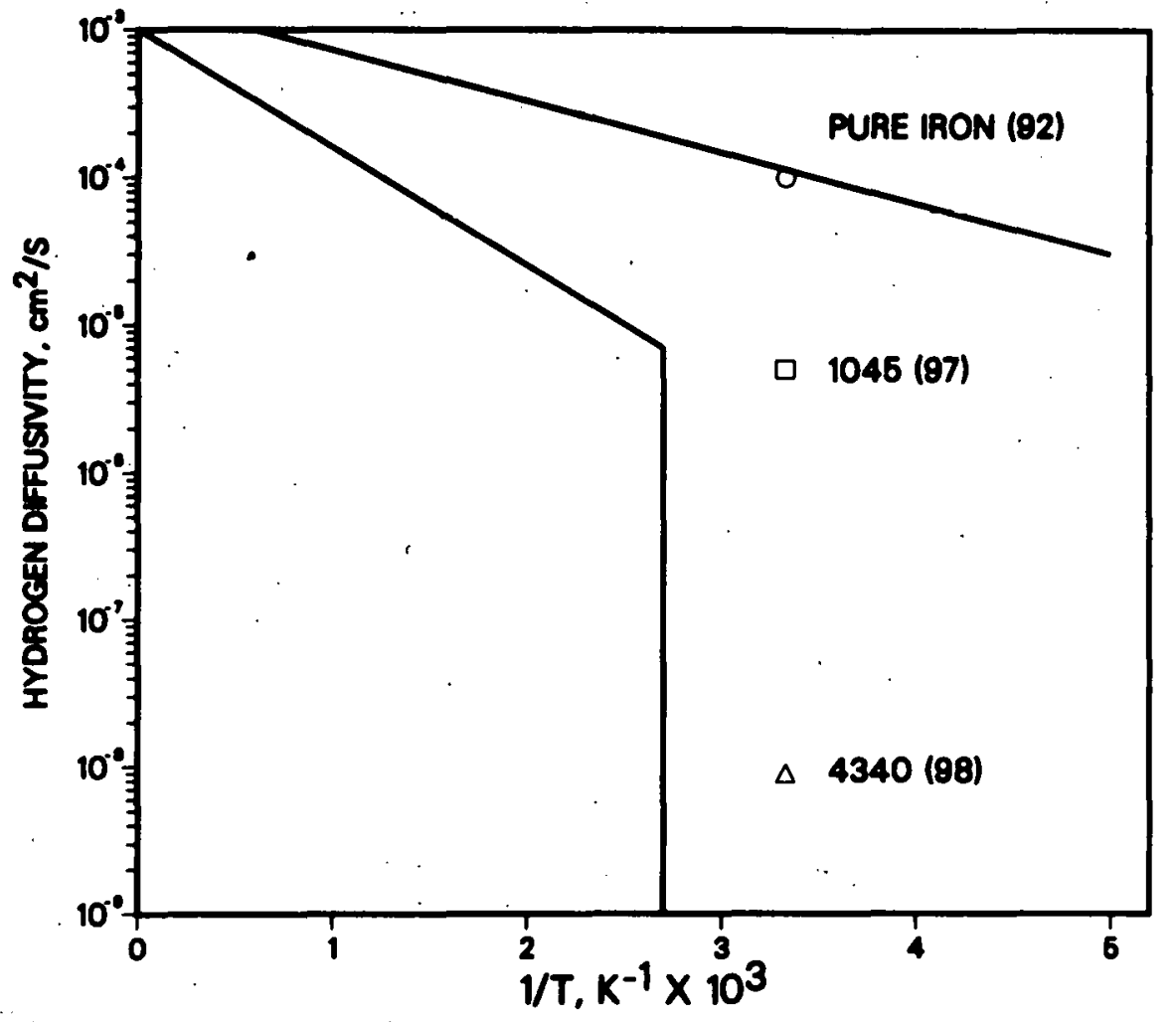

Figure 10. The temperature behavior of hydrogen diffusivity for a number of iron and steel alloys. The solid lines represent the boundary curves for the data of Volkl and Alefeld. 81 
Hydrogen trapping can significantly alter the effective diffusivity of hydrogen and thus crack growth rates. ${ }^{1}$ Studies are needed to quantitatively determine the effects of trapping on hydrogen diffusion. A number of studies ${ }^{75}, 101-102$ attempt to model the effect of trapping on diffusivity. With a low hydrogen occupancy of trap sites, the effective diffusivity of hydrogen is independent of concentration and is reduced in proportion to the amount of hydrogen trapped. When the hydrogen concentration in traps is high, diffusivity is a function of hydrogen concentration. In this situation, it is difficult to obtain explicit solutions of diffusion equations. Terms for hydrogen sources and sinks must be included. 89

Based on trap binding energies, Hirth ${ }^{42}$ proposes that hydrogen traps will unsaturate at some critical temperature. The critical temperature depends on the pressure, or equivalent chemical potential, and whether the system is open or closed. This provides a possible explanation for the dramatic increase in hydrogen-induced thresholds near ambient temperatures. Further study is needed on both internal and external hydrogen environments to determine hydrogen trap effects and their relationship to the temperature behavior of thresholds.

Summary and Recommendations

This review examined various areas of HE/SCC for which data is either ambiguous, contradictory or non-existant. Fundamental research is required to fully understand the following important aspects:

(1) Impurity segregation and hydrogen interactions. Recent studies do not establish if grain boundary impurities sensitize a preferred path for hydrogen-induced cracking or if impurity and hydrogen effects are additive. Careful experimentation on segregation effects is needed to change grain boundary impurity concentrations while maintaining a constant microstructure and yield strength. Use of high strength material such as austenitic, ferritic or martensitic stainless steel should reveal the effects of both impurity elements and hydrogen on intergranular fracture.

Impurities, such as sulfur, can also act as a catalyst for anodic dissolution, thus enhancing hydrogen generation and absorption in some aqueous solutions. Hydrogen introduced under these conditions may alter the grain boundary chemistry and structure, thereby altering susceptibility. The effect of grain boundary impurities/environmental interactions on grain boundary chemistry, structure and susceptibility needs to be studied and compared for a number of environments.

(2) Grain Size effects. Several studies show various effects of grain size on hydrogen-induced thresholds. This behavior may be the result of a variation in grain boundary impurity concentration. To isolate the effects of grain size on $\mathrm{HE} / \mathrm{SCC}$, a study would require varying the grain size while keeping the grain boundary concentration, yield strength and microstructure constant. 
(3) Fracture initiation sites. Recent studies show that fracture initiates at different sites for internal and external hydrogen environments. This change in fracture behavior could account for HE/SCC susceptibility differences between various environments. A study using autoradiography could determine concentration profiles and hydrogen locations under an applied stress and relate fracture sites to $\mathrm{HE} / \mathrm{SCC}$.

(4) Hydrogen transport. Disagreement exists on the role of dislocation and diffusive transport of hydrogen in hydrogen-induced cracking. A study incorporating various loading modes and autoradiography possibiy could define the contribution of each transport mechanism to the fracture process.

(5) Thresholds at high hydrogen gas pressures. Thresholds in hydrogen gas at high pressures are independent of pressure. Several explanations have been proposed to interpret this. A systematic study of thresholds and crack growth rates for one alloy over a wide range of pressures and temperatures could help determine the governing mechanisms of crack growth.

(6) Trapping effects. Trapping can alter crack growth behavior and $\mathrm{HE} / \mathrm{SCC}$ susceptibility. Previous studies on Fe-C-Ti systems need to be expanded to other alloy systems. Hydrogen trapping under an applied stress needs to be determined and related to hydrogen diffusivity and susceptibility. 


\section{ACKNOWLEDGMENTS}

The author wishes to thank A. J. West, Sandia National Laboratories, Prof. W. W. Gerberich, University of Minnesota and Prof. M. R. Louthan, Virginia Polytechnical Institute for their helpful discussions. 


\section{References}

1. W. W. Gerberich: Hydrogen in Metals, I. M. Bernstein and A. W. Thompson, eds., ASM, 1974, p. 115.

2. A. W. Thompson: Environment-Sensitive Fracture of Engineering Materials, Z. A. Foroul is, ed., AIME, 1979, p. 379.

3. A. W. Thompson and I. M. Bernstein: Advances in Corrosion Science and Technology, vol. 7, M. G. Fontana and R. W. Staehle, eds., Plenum Pub. Co., 1980, p. 53.

4. I. M. Bernstein and A. W. Thompson: Int. Met. Rev., 1976, vol. 21, p. 269.

5. J. F. Lessar and W. W. Gerberich: Met. Trans. A, 1976, vo1. 7A, p. 953.

6. C. L. Briant, H. C. Feng and C. J. McMahon: Met. Trans. A, 1978, vol. $9 A$, p. 625 .

7. C. J. McMahon: Mat. Sci. Eng., 1976, vol. 25, p. 233.

8. J. E. Costa and A. W. Thompson: Met. Trans. A, 1981, vo1. 12A, p. 761.

9. H. Chaung, J. B. Lumsden and R. W. Staehle: Met. Trans. A, 1979, vol. $10 \mathrm{~A}$, p. 1853.

10. R. M. Latanision, 0. H. Gastine and C. R. Compeau:

Environment-Sensitive Fracture of Engineering Materials, Z. A.

Foroulis, ed., AIME, 1979, p. 48.

11. S. K. Banerji, C. J. McMahon and H. C. Feng: Met. Trans. A, 1978, vol. 9A, p. 237.

12. C. S. Carter: Corrosion, 1969, vol. 25, p. 423.

13. R. P. M. Proctor and H. W. Paxton: Trans. ASM, 1962, vol. 62, p. 989.

14. I. M. Bernstein: Met. Trans., 1970, vol. 1, p. 3143.

15. J. A. Marquez, I. Matsushima and H. H. Uhlig: Corrosion, 1970, vol. 26 , p. 215 .

16. H. Uhlig, K. E. Perumal and M. Talerman: Corrosion, 1974, vol. 30, p. 229.

17. G. Sandoz: Met. Trans., 1971, vol. 2, p. 1055.

18. G. Sandoz: Met. Trans., 1972, vol. 3, p. 1169.

19. R. M. Latanision and R. W. Staehle: Fundamental Aspects of Stress Corrosion Cracking, R. W. Staehle, ed., NACE, 1969, p. 214. 
20. P. Lillys and A. E. Nehrenberg: Trans. ASM, 1956, 48, p. 327.

21. C. L. Briant: Met. Trans. A, 1978, vol. 9A, p. 731.

22. M. 0. Speide1: Met. Trans. A, 1981, vol. 12A, p. 779.

23. G. M. Pressouyre and I. M. Bernstein: Acta. Met., 1979, vol. 27, p. 89 .

24. A. W. Loginow and J. F. Bates: Corrosion, 1969, vol. 25, p. 15.

25. R. 0. Ritchie, M. H. Cedeno, V. F. Zackay and E. R. Parker: Met. Trans. A, 1978, vol. 9A, p. 35.

26. B. D. Craig and G. Krauss: Met. Trans. A, 1980, vol. 11A, p. 1799.

27. C. L. Briant and S. K. Banerji: Met. Trans. A, 1979, vol. 10A, p. 1151 .

28. H. H. Uhlig, R. A. White and J. Lincoln: Acta Met., 1957, vol. 5, p. 473.

29. F. S. Lang: Corrosion, 1962, vol. 18, p. 378 t.

30. C. L. Briant: Met. Trans. A, 1979, vol. 10A, p. 181.

31. J. Kameda and C. J. McMahon: Met. Trans. A, 1981, vol. 12A, p. 31.

32. R. Viswanathan and S. J. Hudak: Met. Trans. A, 1977, vo1. 8A, p. 1633.

33. N. Bandyopadhyay and.C. J. McMahon: "The Mechanism of Hydrogen-Induced Brittle Fracture in 4340-Type Steels", presented at the TMS-AIME Fal1 Meeting, Oct. 5-9, 1980, Pittsburgh, PA.

34. W. W. Gerberich, Y. T. Chen and C. St. John: Met. Trans. A, 1975, vol. 6 A, p. 1485.

35. C. L. Briant and S. K. Banerji: Met. Trans. A, 1979, vol. 10A, p. 1729 .

36. J. Kámeda and C. J. McMahon: Met. Trans. A, 1980, vo1. 11A, p. 91.

37. H. Ohtani, H. C. Feng, C. J. McMahon and R. A. Mulford: Met. Trans. A, 1976, vol. 7A, p. 87.

38. A. K. Cianelli, H. C. Feng, A. H. Vcisik and C. J. McMahon: Met. Trans. A, 1977, vol. 8A, p. 1059.

39. S.K. Hwang and J. W. Morris: Met. Trans. A, 1980, vol. 11A, p. 1197.

40. A. W. Thompson and J. A. Brooks: Met. Trans. A, 1975, vol. 6A, p. 1431 . 
41. J. A. Brooks: Unpublished research, Sandia National Laboratories, Livermore, CA.

42 J. P. Hirth: Met. Trans. A, 1980, vol. 11A, p. 861.

43. R. J. Asaro, A. J. West and W. A. Tiller: Stress Corrosion Cracking and Hydrogen Embrittlement of Iron Base Alloys, R. W. Staehle, J. Hockmann, R. D. McCright and J. E. Slater, eds., NACE, 1977, p. 1115.

44. H. Hanninen and T. Hakkarainen: Met. Trans. A, 1979, vol. 10A, p. 1196.

45. A. J. Russell and D. Tromans: Met. Trans. A, 1981, vol. 12A, p. 613.

46. A. J. West and J. H. Holbrook: Hydrogen Effects in Metals, I. M. Bernstein and A. W. Thompson, eds., AIME, 1981, p. 607.

47. J. C. Swearengen, F. A. Greulich and J. Lipkin: Proceedings of the Conf. On Environmental Degradation of Engineering Materials, 1981, to be published.

48. C. G. Rhodes and A. W. Thompson: Met. Trans. A, 1977, vol. 8A, p. 949.

49. R. E. Stoltz and A. J. West: Hydrogen Effects in Metals, I. M. Bernstein and A. W. Thompson, eds., AIME, 1981, p. 541.

50. R. E. Hanneman, P. R. Rao and J. C. Danko: Environment-Sensitive Fracture of Engineering Materials, Z. A. Foroulis, ed., AIME, 1979, p. 153.

51. C. Chen, A. W. Thompson and I. M. Bernstein: Met. Trans. A, 1980, vol. $11 \mathrm{~A}$, p. 1723.

52. W. A. Baeslock III, W. F. Savage and D. J. Duquette: Met. Trans. A, 1979, vol. 10A, p. 1429.

53. J. A. Brooks and A. J. West: Met. Trans. A, 1981, vo1. 12A, p. 213.

54. J. A. Brooks, A. J. West and A. W. Thompson: Conference on Hydrogen Effects in Metals, Poster Session, Jackson Hole, Wy, 1980.

55. R. 0. Ritchie and R. M. Horn: Met. Trans. A, 1978, vol. 9A, p. 331.

56. R. 0. Ritchie, B. Francis, and W. L. Server: Met. Trans. A, 1976, vol. $7 A$, p. 831 .

57. T. D. Lee, T. Goldenberg, and J. P. Hirth: Met. Trans. A, 1979, vol. $10 A$, p. 439.

58. W. W. Gerberich and Y. T. Chen: Met. Trans. A, 1975, vo1. 6A, p. 271. 
59. G. W. Simmons, P. S. Pao and R. P. Wei: Met. Trans. A, 1978, vol. 9A, p. 1147 .

60. R. P. Gangloff and R. P. Wei: Met. Trans. A, 1977, vol. 8A, p. 1043.

61. R. A. Oriani and P. H. Josephic: Acta. Met., 1977, vol. 25, p. 979.

62. R. A. Oriani and P. H. Josephic: Acta. Met., 1974, vol. 22, p. 1065.

63. R: J. Walter and W. T. Chandler: NASA Report CR-124410, 1973, Rocketdyne Division, Rockwell Int., Canoga Park, CA.

64. A. W. Loginow and E. H. Phelps: Corrosion, 1975, vol. 31, p. 404.

65. W. W. Gerberich, J. Garry and J. F. Lessar: Effect of Hydrogen on the Behavior of Materials; A. W. Thompson and I. M. Bernstein, eds., AIME, 1976 , p. 70.

66. G. C. Story: Ph.D. Thesis, University of California, Davis Ca., June 1980 .

67. M. W. Perra: Environmental Degradation of Engineering Materials in Hydrogen, M. R. Louthan, R. P. McNitt and R. D. Sisson, eds., VPI, 1981 , p. 321 .

68. M. I. Baskes, C. F. Melius and W. D. Wilson: Hydrogen Effects in Metals, I. M. Bernstein and A. W. Thompson, eds., 1981, p. 67.

69. K. N. Akhurst and T. J. Baker: Met. Trans. A, 1981, vol. 12A, p. 1059.

70. M. J. Stowel1, J. Davenport and K. J. Gradwel1: Metal Science, 1978, vol. 12, p. 192 .

71. W. A. Spitzig: Acta Met., 1979, vo1. 27, p. 523.

72. W. A. Spitzig, R. J. Sober and 0. Richmond: Met. Trans. A, 1976, vol. 7A, p. 1703.

73. C. H. Robbins and A. S. Wronski: Acta Met., 1978, vol. 26, p. 1061.

74. M. W. Perra and R. E. Stoltz: Hydrogen Effects in Metals, I. M: Bernstein and A. W. Thompson, eds., 1981, p. 645.

75. M. Lu, P. S. Pao, T. W. Weir, G. W. Simmons and R. P. Wei: Met. Trans. A, vol. 12A, p. 805 .

76. C. M. Ransom and P. J. Ficalora: Met. Trans. A, 1980, vol. 11A, p. 801 .

77. A. W. Thompson: Mat. Sçi. Eng., 1980, vol. 43, p. 41.

78. S. R. Bala and D. Tromans: Met. Trans. A, 1978, vol. 9A, p. 1125. 
79. J. A. S. Green; H. W. Hayden and W. S. Montague: Hydrogen Effects on Behavior of Materials, A. W. Thompson and I. M. Bernstein, eds., AIME, 1976 , p. 200.

80. D. P. WI lliams, P. S. Pao and R. P. Wei: Environment-Sensitive * Fracture of Engineering Materials, Z. A. Foroulis, ed., AIME, 1979, p. 3.

81. J. Kilien, A. W. Thompson, I. M. Bernstein and R. J. Richards: Met. Trans. A, 1976, vol. 7A, p. 821.

82. J. A. Donovan: Met. Trans. A, 1976, vol. 7A, p. 1677.

83. H. H. Johnson and J. P. Hirth: Met. Trans. A, 1976, vol. 7A, p. 1543.

84. H. H. Johnson, N. Quick and A. J. Kumnick: Scripta Met., 1979, vol. 13 , p. 67 .

85. T. Asaoka, G. Lapasset, M. Aucouturier and P. Lacombe: Corrosion, 1978, vol. 34, p. 39 .

86. M. R. Louthan, G. R. Caskey, J. A. Donovan and D. E. Raw1: Mat. Sci. Eng., 1972, vol. 10, p. 357 .

87. M. R. Louthan: Effect of Hydrogen and Behavior of Materials, A. W. Thompson and I. M. Bernstein, eds., 1976, p. 53.

88. A. J. West and M. R. Louthan: Met. Trans. A, vol. 10A, 1979, p. 1675.

89. J. C. M. Li, R. A. Oriani and L. S. Darken: Zeit. fur Physik. Chemie, Neue Folge, 1966, vol. 49, p. 271 .

90. H. A. Wriedt and R. A. Oriani: Acta Met., 1970, vol. 18, p. 753.

91. C. St. John and W. W. Gerberich: Met. Trans., 1973, vol. 4, p. 589.

92. A. J. Kumnick and H. H. Johnson: Acta Met., 1977, vol. 25, p. 891.

93. N. R. Quick and H. H. Johnson: Acta Met., 1978, vol. 26, p. 903.

94. A. J. Kumnick and H. H. Johnson: Met. Trans A, vol. 6A, p. 1087.

95. R. A. Oriani: Fundamental Aspects of Stress Corrosion Cracking, R. W. Staehle, ed., NACE, 1969, p. 32.

96. J. Volkl and G. Alefeld: Hydrogen in Metals, Topics in Applied Physics, G. Alefeld and J. Volk1, eds., 1978, vol. 28, p. 321.

97. W. M. Robertson and A. W. Thompson: Met. Trans A, 1980, vol. 11A, p. 553.

98. W. Beck, J. O'M. Bockris, J. McBreen and L. Nanis: Proc. Royal Soc. London, 1066, vol. 290A, p. 220. 
99. G. W. Powel1, J. D. Braun, K. F. Chaney and G. L: Downs: Corrosion, 1970, vol: 26, p. 223.

100. G. Thomas: Hydrogen Effects in Metals, I. M. Bernstein and A. W. Thompson, eds., 1981, p. 77 .

101. R. A. Oriani: Acta Met., 1970, vol. 18, p. 147.

102. G. M. Pressouyre and I. M. Bernstein: Met. Trans. A, 1978, vo1. 9A, p. 1571 . 
UNLIMITED RELEASE

\section{Initial Distribution}

George R. Caskey, Jr.

E.I. duPont de Nemours

Savannah River Laboratory

Aiken, SC 29808

W. W. Gerberich

Dept. of Chem. Eng. \& Mat. Sci.

University of Minnesota

Minneapolis, MN 55455

M. R. Louthan, Jr.

Materials Engineering Department

VPI \& SU

Blacksburg, VA 24061

M. J. Davis, 5830

R. W. Rohde, 5832

C. H. Carnes, 5835

N. J. Magnani, 5840

D. W. Schaefer, 5841

T. B. Cook, 8000; Attn:

D. M. 01 son, 8100

A. N. Blackwel1, 8200

W. E. Alzheimer, 8120

L. Gutierrez, 8400

B. Zinke, 8123

M. Perra, 8123

B. F. Murphey, 8300

D. M. Schuster, 8310

W. M. Garrison, 8312

R. W. Mar, 8313

A. J. West, 8314

N. R. Moody, 8314 (20)

J. M. Hyzak, 8314

B. C. Odegard, 8314

S. L. Robinson, 8314

J. C. Lippold, 8314

J. R. Spingarn; 8314

L. A. West, 8315

J. C. Swearengen, 8316

J. Brooks, 8316

R. L. Rinne, 8320

G. W. Anderson, 8330

W. Bauer, 8340

W. Wilson, 8341

M. I. Baskes, 8341

P. L. Mattern, 8342

C. F. Melius, 8343

W. B. Gauster, 8347 
D. J. Havlik, 8441

W. R. Hoover, 8442

H. Hanser, 8445

Publications Division, 8265, for TIC (2)

Publications Division, 8265/Technical Library Processes Division, 3141

Technical Library Processes Division, 3141 (3)

M. A. Pound, 8214, for Central Technical Files (3) 

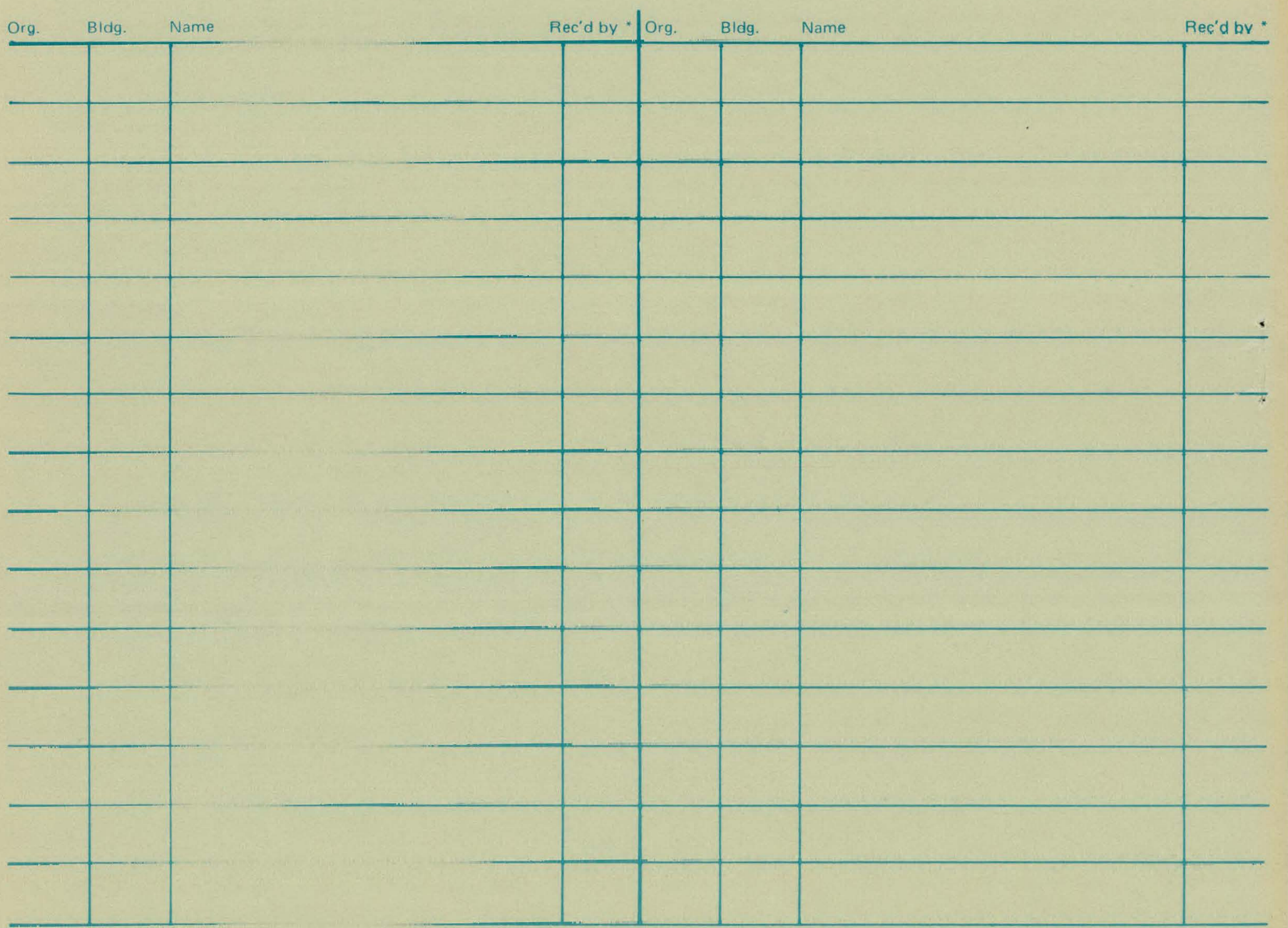